\title{
Human non-small cell lung cancer cells can be sensitized to camptothecin by modulating autophagy
}

\author{
YI-HAN CHIU $^{1 *}$, SHIH-HSIEN HSU ${ }^{2 *}$, HSIAO-WEI HSU ${ }^{2,3}$, KUO-CHIN HUANG $^{4}$, \\ WANGTA LIU ${ }^{3}$, CHANG-YI WU ${ }^{3,5}$, WEI-PANG HUANG ${ }^{6}$, JEFF YI-FU CHEN ${ }^{3}$, \\ BING-HUNG CHEN ${ }^{3,7,8}$ and CHIEN-CHIH CHIU ${ }^{2,3,5,9,10}$
}

\author{
${ }^{1}$ Department of Nursing, St. Mary's Junior College of Medicine, Nursing and Management, Yilan 266; \\ ${ }^{2}$ Graduate Institute of Medicine; ${ }^{3}$ Department of Biotechnology, Kaohsiung Medical University, Kaohsiung 807; \\ ${ }^{4}$ Holistic Education Center, Mackay Medical College, New Taipei City 252; ${ }^{5}$ Department of Biological Sciences, \\ National Sun Yat-sen University, Kaohsiung 804; ${ }^{6}$ Department of Life Science, National Taiwan University, \\ Taipei 106; ${ }^{7}$ Department of Medical Research, Kaohsiung Medical University Hospital, \\ Kaohsiung Medical University, Kaohsiung 807; ${ }^{8}$ The Institute of Biomedical Sciences, \\ National Sun Yat-sen University, Kaohsiung 804; ${ }^{9}$ Research Center for Environmental Medicine, \\ Kaohsiung Medical University; ${ }^{10}$ Translational Research Center, Cancer Center, \\ Department of Medical Research, Kaohsiung Medical University Hospital, \\ Kaohsiung Medical University, Kaohsiung 807, Taiwan, R.O.C.
}

Received September 29, 2017; Accepted June 1, 2018

DOI: $10.3892 /$ ijo.2018.4523

\begin{abstract}
Lung cancer is a prevalent disease and is one of the leading causes of mortality worldwide. Despite the development of various anticancer drugs, the prognosis of lung cancer is relatively poor. Metastasis of lung cancer, as well as chemoresistance, is associated with a high mortality rate for patients with lung cancer. Camptothecin (CPT) is a well-known anticancer drug, which causes cancer cell apoptosis via the induction of DNA damage; however, the cytotoxicity of CPT easily reaches a plateau at a relatively high dose in lung cancer cells, thus limiting its efficacy. The present study demonstrated that CPT may induce autophagy in two human non-small cell lung cancer cell lines, H1299 and H460. In addition, the results of a viability assay and Annexin V staining revealed that CPT-induced autophagy could protect lung cancer cells from programmed cell death. Conversely, the cytotoxicity of CPT was increased when autophagy was blocked by 3-methyladenine treatment. Furthermore, inhibition of autophagy enhanced the levels of CPT-induced DNA damage in the lung cancer cell lines. Accordingly, these findings suggested that
\end{abstract}

Correspondence to: Dr Chien-Chih Chiu, Department of Biotechnology, Kaohsiung Medical University, 100 Shih-Chuan 1st Road, Kaohsiung 807, Taiwan, R.O.C.

E-mail: cchiu@kmu.edu.tw

*Contributed equally

Key words: camptothecin, DNA damage, chemoresistance, targeting autophagy, apoptosis autophagy exerts a protective role in CPT-treated lung cancer cells, and the combination of CPT with a specific inhibitor of autophagy may be considered a promising strategy for the future treatment of lung cancer.

\section{Introduction}

Lung cancer is one of the leading causes of mortality worldwide. Even though numerous anticancer drugs have been developed, it remains a challenge to effectively treat lung cancer without increasing chemoresistance. Non-small cell lung cancer (NSCLC) is a type of lung cancer that is further classified into three histopathological subtypes: Adenocarcinoma, squamous cell carcinoma and large-cell carcinoma (LCC) (1). NSCLC accounts for $80 \%$ of lung cancer cases, and of these, $\sim 10 \%$ are LCC (2). LCC occurs in the lungs and is characterized by poor differentiation, rapid growth and early metastasis $(3,4)$. These cancers also have an aggressive pattern and are associated with a poorer prognosis. The 5-year survival rate for patients with stage III/IV LCC is $<10 \%$ (5). Although LCC of the lung is a relatively uncommon type of lung cancer, a better understanding of the molecular and cellular biology of LCC, the mechanisms underlying LCC drug resistance and the possible molecular pathway associated with autophagy-mediated drug resistance may identify more effective NSCLC therapeutic strategies and targets. Therefore, the present study used two LCC cell lines, H1299 and H460.

Camptothecin (CPT), which is a natural compound originally derived from the Asian tree Camptotheca acuminata, was synthesized by Wall and Wani in 1966 (6). CPT is able to form a stable tertiary structure with DNA and topoisomerase I, thus resulting in formation of the topoisomerase I-CPT complex, which inhibits topoisomerase I and results in DNA 
damage and cell death (7). Recent studies have revealed that $\mathrm{CPT}$ and its derivatives exert broad antitumor activity against various tumors cells in vitro and in vivo. CPT and its derivatives have been reported to exhibit anticancer activities against various types of cancer cells, including lung cancer (8), gastric cancer (9), esophageal cancer (10), colorectal cancer (11) and breast cancer (12). Oral topotecan has been used as a second-line medication for the treatment of metastatic ovarian cancer (13) and small-cell lung cancer (14). Furthermore, irinotecan-based chemotherapy improves overall response rate, overall survival and progression-free survival, and has been recommended as a first-line treatment in Asian patients with stage IIIB/IV NSCLC (15).

Although the clinical use of CPT derivatives has exhibited efficacy in the treatment of the aforementioned types of cancer, de novo and developed clinical resistance to these drugs is common. The mechanism underlying the resistance of cancer cells to CPT-based anticancer drugs remains to be fully elucidated, since the resistance and selectivity towards cancer cells is multifactorial. Sugimoto et al revealed that quantitative reduction of topoisomerase I content contributes to the most frequently occurring events in the development of resistance to CPT in various tumor cell lines (16). In addition, a previous study indicated that the increased expression of ATP-dependent drug transporters, such as ATP-binding cassette subfamily $\mathrm{C}$ member 4 and ATP binding cassette subfamily $\mathrm{G}$ member 2 (ABCG2), is sufficient to confer resistance of lung cancer cells to the CPT-based anticancer drugs irinotecan and topotecan (17). Furthermore, it has been reported that breast cancer induces resistance to topotecan and irinotecan via regulation of the cell cycle and DNA repair activity (18). Although numerous novel therapies have been developed, the prognosis of patients has not significantly improved, and chemoresistance is one of the main reasons for the low survival of patients with lung cancer. CPT derivatives are also affected by chemoresistance during the treatment of lung cancer. For example, an increase in ABCG2 expression is often correlated with irinotecan and topotecan resistance, and may result in clinical failure in patients with advanced NSCLC (19). Therefore, the present study applied CPT as a model to determine the mechanisms underlying chemoresistance in NSCLC cells.

Autophagy is a cellular degradation response to various types of stress, including starvation, hypoxia, reactive oxygen species (ROS) and DNA damage $(20,21)$. Membrane receptors receive signals, which are communicated to the cell interior, thus resulting in activation of autophagy, which degrades dysfunctional proteins and organelles, in order to yield more energy for adaptation to adverse environments and avoid cell apoptosis (22). Therefore, cell fate depends on the association between apoptosis and autophagy. According to previous studies, when cells are treated with chemotherapy, autophagy serves a major role in chemoresistance (23). For example, celecoxib is able to suppress autophagic flux by preventing lysosome function, and strengthens the cytotoxicity of imatinib in imatinib-resistant myeloid leukemia cells (24). In addition, human epidermal growth factor receptor 2-overexpressing breast cancer cells exposed to trastuzumab exhibit increased autophagy, and protect breast cancer cells from the inhibitory effects of trastuzumab. Conversely, the blockade of autophagosome formation/function significantly enhances the growth inhibitory activity of trastuzumab in trastuzumabrefractory breast cancer cells (25). These findings suggest that inhibiting autophagy may be a novel target for increasing drug effects.

The present study aimed to examine the effects of CPT on cell viability, migration, apoptosis and autophagy in the H1299 NSCLC cell line. The results demonstrated that CPT exerted limited cytotoxic and anti-metastatic effects on H1299 cells. In addition, apoptosis and DNA damage were not increased following CPT dose accumulation. However, CPT induced the increased formation of autophagosomes in the H1299 NSCLC cell line in a dose-dependent manner. Furthermore, the present study revealed that the autophagy inhibitor, 3-methyladenine (3-MA), was able to suppress CPT-induced autophagy. The results demonstrated that 3-MA enhanced the cytotoxicity of CPT in CPT-resistant H1299 cells. Accordingly, 3-MA may serve as a novel agent to enhance the antitumor activity of conventional therapeutic agents in CPT-resistant H1299 cells.

\section{Materials and methods}

Cell culture. Human NSCLC cell lines H1299 and H460 were generously provided by Dr K. Fang (National Taiwan Normal University, Taipei, Taiwan). H1299 and H460 cells were grown in Dulbecco's modified Eagle's medium (DMEM; Gibco; Thermo Fisher Scientific, Inc., Waltham, MA, USA), supplemented with $10 \%$ fetal bovine serum (FBS; Gibco; Thermo Fisher Scientific, Inc.), $100 \mu \mathrm{g} / \mathrm{ml}$ streptomycin and $100 \mathrm{U} / \mathrm{ml}$ penicillin (Gibco; Thermo Fisher Scientific, Inc.), at $37^{\circ} \mathrm{C}$ in a humidified incubator containing $5 \% \mathrm{CO}_{2}$. Cell morphology was observed under an inverted light microscope.

Source of CPT and 3-MA, and half maximal inhibitory concentration $\left(I C_{50}\right)$ values of $C P T$. CPT and 3-MA were purchased from Sigma-Aldrich (Merck KGaA, Darmstadt, Germany). CPT was dissolved in dimethyl sulfoxide (DMSO) to form a stock concentration of $5 \mathrm{mM}$, and 3-MA was freshly dissolved in $\mathrm{ddH}_{2} \mathrm{O}$ at $20 \mathrm{mM}$. Cells were treated with $0.5,1$, 2 and $5 \mu \mathrm{M} \mathrm{CPT}$, and co-treated with $0.1,0.5,1$ and $5 \mathrm{mM}$ 3-MA for $24 \mathrm{~h}$ at at $37^{\circ} \mathrm{C}$ in a humidified incubator containing $5 \% \mathrm{CO}_{2}$. To determine the $\mathrm{IC}_{50}$ values of CPT, $3 \times 10^{3} \mathrm{H} 1299$ or $\mathrm{H} 460$ cells/well in 96-well plates were used. After $48 \mathrm{~h}$ of plating, cells were treated with various doses of CPT $(0.01$, $0.1,0.5,1,10,50,100$ or $200 \mu \mathrm{M}$ ) for $24 \mathrm{~h}$. The cells were incubated for $4 \mathrm{~h}$ with DMEM containing $0.5 \% \mathrm{FBS}$ and $0.5 \mathrm{mg} / \mathrm{ml} \mathrm{MTT}$ at $37^{\circ} \mathrm{C}$ in an atmosphere containing $5 \% \mathrm{CO}_{2}$ to determine the number of surviving cells. After removing the medium containing MTT and replacing with $100 \mu \mathrm{l}$ DMSO, absorbance was recorded at $570 \mathrm{~nm}$ using a Multiskan Ascent microplate reader (Thermo Fisher Scientific, Inc.). The $\mathrm{IC}_{50}$ values of each agent were determined using Ascent Software, version 2.6 (Thermo Fisher Scientific, Inc.).

Cell viability assay. A cell viability assay was performed as described previously with slight modifications (26). Briefly, $5 \times 10^{4} \mathrm{H} 1299$ and H460 cells/well were seeded in 12-well plates, and were treated with DMSO as a vehicle or with various concentrations of CPT for $24 \mathrm{~h}$, respectively. Subsequently, the 
cells were suspended in $0.2 \%$ trypan blue and counted using a Countess automated cell counter (Invitrogen; Thermo Fisher Scientific, Inc.), according to the manufacturer's protocol.

Cell migration assays. The migration of $\mathrm{H} 1299$ and H460 cells was determined using wound-healing assays as previously described (27). Briefly, for wound-healing assays, 3×10 ${ }^{5} \mathrm{H} 1299$ and $\mathrm{H} 460$ cells/well were seeded in 12-well plates, and were grown overnight until they reached $\sim 95 \%$ confluence, after which wound gaps were generated using a sterile pipette tip. Cellular debris was removed with PBS and cells were incubated in medium containing $0.5,1,2$, and $5 \mu \mathrm{M}$ CPT. The wound-healing ability of the cells was documented after $16 \mathrm{~h}$ using the Nikon Eclipse TE2000U microscope (Nikon Corporation, Melville, NY, USA). The migration distance was assessed using TScratch software, version 1.0 (MathWorks Inc., Natick, MA, USA). The migration rate was calculated according to the relative cell migration area for each treatment.

Annexin V staining. $\mathrm{H} 1299$ and $\mathrm{H} 460$ cells $\left(1 \times 10^{5}\right.$ per well in a 6-well plate) were collected following incubation with CPT and/or 3-MA for $24 \mathrm{~h}$. The cells were washed with PBS and were then resuspended in Annexin V binding buffer $[140 \mathrm{mM}$ $\mathrm{NaCl}, 10 \mathrm{mM}$ HEPES-NaOH (pH 7.4) and $2.5 \mathrm{mM} \mathrm{CaCl}$ ]. Following $300 \mathrm{x}$ g centrifugation for $5 \mathrm{~min}$, the cells were incubated with Annexin V binding buffer containing $1.25 \mathrm{ml}$ fluorescein isothiocyanate (FITC)-conjugated Annexin V and PI (BD Pharmingen; BD Biosciences, San Jose, CA, USA) at room temperature for $15 \mathrm{~min}$ in the dark. Data acquisition and analysis were performed using the BD Accuri ${ }^{\mathrm{TM}}$ C6 flow

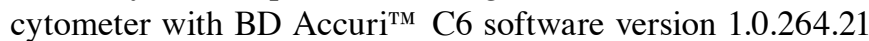
(both from BD Biosciences).

Western blot analysis. A total of $1 \times 10^{6}$ cells per $10 \mathrm{~cm}$ dish were treated with the indicated concentrations of CPT and/or 3-MA for $24 \mathrm{~h}$. Cells were lysed with radioimmunoprecipitation assay lysis buffer (cat. no. 20-188; EMD Millipore, Billerica, MA, USA) containing 0.05 M Tris- $\mathrm{HCl}$ (pH 7.4), $0.15 \mathrm{M} \mathrm{NaCl}, 0.25 \%$ deoxycholic acid, $1 \% \mathrm{NP}-40,1 \mathrm{mM}$ EDTA and a protease inhibitor mixture (Sigma-Aldrich; Merck KGaA). After one freeze-thaw cycle, cell lysates were centrifuged at $14,000 \mathrm{x}$ g for $30 \mathrm{~min}$ at $4^{\circ} \mathrm{C}$. Proteins were collected and concentration was determined using the Pierce $^{\mathrm{TM}}$ Bicinchoninic Acid Protein Assay kit (Thermo Fisher Scientific, Inc.) before boiling with the electrophoresis sample buffer for $5 \mathrm{~min}$. The $25 \mu \mathrm{g}$ sample lysate was mixed with the reducing sample buffer and resolved by $10 \%$ SDS-PAGE. Proteins were then blotted on polyvinylidene fluoride membranes (Pall Corporation, Port Washington, NY, USA) and blocked for $1 \mathrm{~h}$ in blocking solution (5\% non-fat dry milk, $1 \%$ Tween-20 in PBS) at room temperature. Membranes were washed with Tris-buffered saline with $0.1 \%$ Tween-20 (TBS-T). Proteins were determined using primary antibodies against human caspase-3 (1:1,000, cat. no. AS-55041; Anaspec Inc., Fremont, CA, USA), human Bax (1:1,000, cat. no. ab32503; Abcam, Cambridge, MA, USA), human PARP (1:1,000, cat. no. 9541; Cell Signaling Technology, Inc., Danvers, MA, USA), human caspase-9 (1:1,000, cat. no. 9501; Cell Signaling Technology, Inc.), phosphorylated-H2A histone family member $\mathrm{X}\left(\mathrm{Ser}^{139}\right)(\gamma \mathrm{H} 2 \mathrm{AX} ; 1: 500$, cat. no. sc-101696;
Santa Cruz Biotechnology, Inc., Dallas, TX, USA), human autophagy-related 3 (Atg3; 1:1,000, cat. no. AP1807c; Abgent, Inc., San Diego, CA, USA), human microtubule-associated proteins 1A/1B light chain 3B (LC3B; 1:1,000, cat. no. 2775; Cell Signaling Technology, Inc.), huaman sequestome-1 (SQSTM)/P62 (1:1,000, cat. no. GTX100685; GeneTex, Inc., Irvine, CA, USA), human lysosomal-associated membrane protein 2 (LAMP2; 1:1,000, cat. no. AM1851b; Abgent, Inc.), human mTOR (1:1,000, cat. no. 1612-S; Epitomics; Abcam), human $\beta$-actin $(1: 8,000$, cat. no. 612656; BD Biosciences) and human GAPDH (1:8,000, cat. no. YH80536; Yao-Hong Biotechnology, Inc., New Taipei City, Taiwan). Each membrane was incubated with appropriate primary antibodies at $4^{\circ} \mathrm{C}$ overnight and washed with PBS containing Tween. After washing with PBS with $0.5 \%$ Tween, blots were incubated with a 1:10,000 dilution of horseradish peroxidase (HRP)-conjugated goat anti-mouse (cat. no. \#20102; Leadgene Biomedical, Inc., Tainan, Taiwan) or goat anti-rabbit IgG (cat. no. \#20202; Leadgene Biomedical, Inc.) antibodies for $1.5 \mathrm{~h}$ at room temperature. The signals of specific proteins were detected using a Western Bright ECL HRP substrate kit (Advansta, Inc., Menlo Park, CA, USA)

Treatment with a pan-caspase inhibitor. To determine whether caspase-mediated apoptosis affected 3-MA-enhanced reductions in the proliferation of CPT-treated cells, the pan-caspase inhibitor Z-VAD-FMK (cat. no. S7023; Selleck Chemicals, Houston, TX, USA) was dissolved in DMSO. Briefly, $5 \times 10^{4}$ NSCLC H1299 cells/well were seeded in a 12-well plate and were pretreated with $50 \mu \mathrm{M}$ Z-VAD-FMK for $2 \mathrm{~h}$ at $37^{\circ} \mathrm{C}$. Subsequently, the cells were treated with CPT/3-MA for $24 \mathrm{~h}$. Cellular viability was determined using the trypan blue exclusion assay, as described previously (28).

Flow cytometric detcetion of $\gamma H 2 A X$. Briefly, cells were collected and fixed in $70 \%$ ethanol at $-20^{\circ} \mathrm{C}$ overnight. Prior to flow cytometry, the ethanol was aspirated, and cells were rinsed with $\mathrm{PBS}$ and incubated with anti- $\gamma \mathrm{H} 2 \mathrm{AX}(1: 100$; cat. no. sc-101696; Santa Cruz Biotechnology, Inc.) dissolved in PBS containing $1 \%$ bovine serum albumin (BSA; cat no. 101-9048-46-8; MDBio, Inc., Taipei, Taiwan) and 0.5\% Triton (BSA-T-PBS) at $4^{\circ} \mathrm{C}$ overnight. The cells were then incubated with FITC-conjugated anti-mouse immunoglobulin G (1:500, cat. no. GTX26816; Genetex, Inc.) dissolved in BSA-T-PBS for $1 \mathrm{~h}$ at $4^{\circ} \mathrm{C}$ in the dark. The cells were then rinsed and suspended in $1 \mu \mathrm{l} 20 \mu \mathrm{g} / \mathrm{ml}$ propidium iodide (PI) containing RNase for $20 \mathrm{~min}$ at $37^{\circ} \mathrm{C}$, and FITC $(\gamma \mathrm{H} 2 \mathrm{AX})$ and PI (DNA content) were quantified using BD Accuri ${ }^{\mathrm{TM}} \mathrm{C} 6$ flow cytometer with BD Accuri ${ }^{\mathrm{TM}}$ C6 software (both BD Biosciences).

Immunofluorescence detection of $\gamma H 2 A X$ nuclear foci. H1299 cells $\left(3 \times 10^{4} /\right.$ well) grown on a 24 -well plate were exposed to various concentrations of 3-MA in the presence of $0.5 \mu \mathrm{M}$ CPT for $24 \mathrm{~h}$ at $37^{\circ} \mathrm{C}$. The cells were then washed with PBS and fixed in $4 \%$ paraformaldehydefor $20 \mathrm{~min}$ at room temperature. The fixed cells were washed twice with PBS, permeabilized with $0.5 \%$ Triton-PBS, blocked with $1 \%$ BSA-PBS and incubated for $2 \mathrm{~h}$ with anti- $\gamma \mathrm{H} 2 \mathrm{AX}$ mouse monoclonal antibodies (cat. no. sc-101696; Santa Cruz Biotechnology, Inc.). The antibodies were then washed off 
A

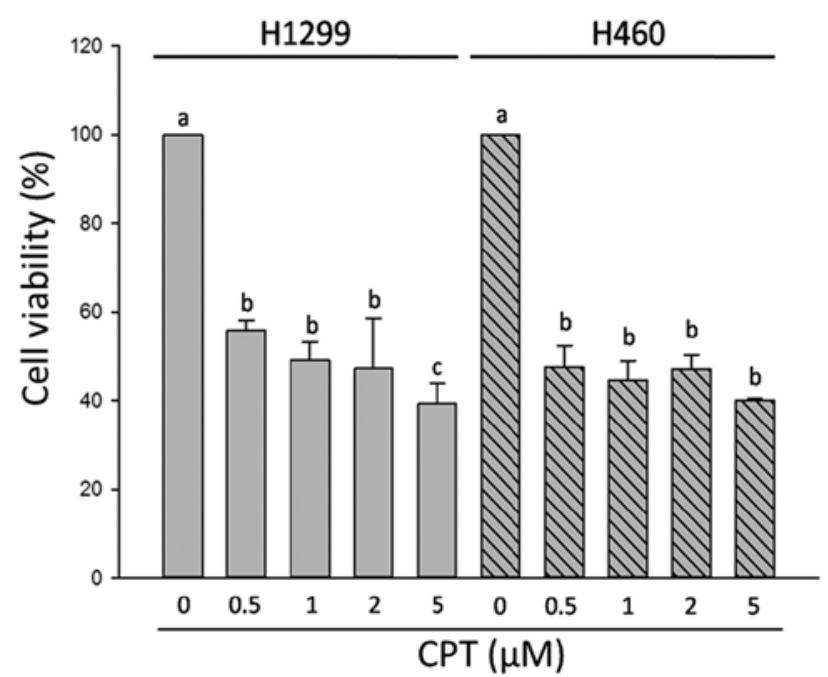

B

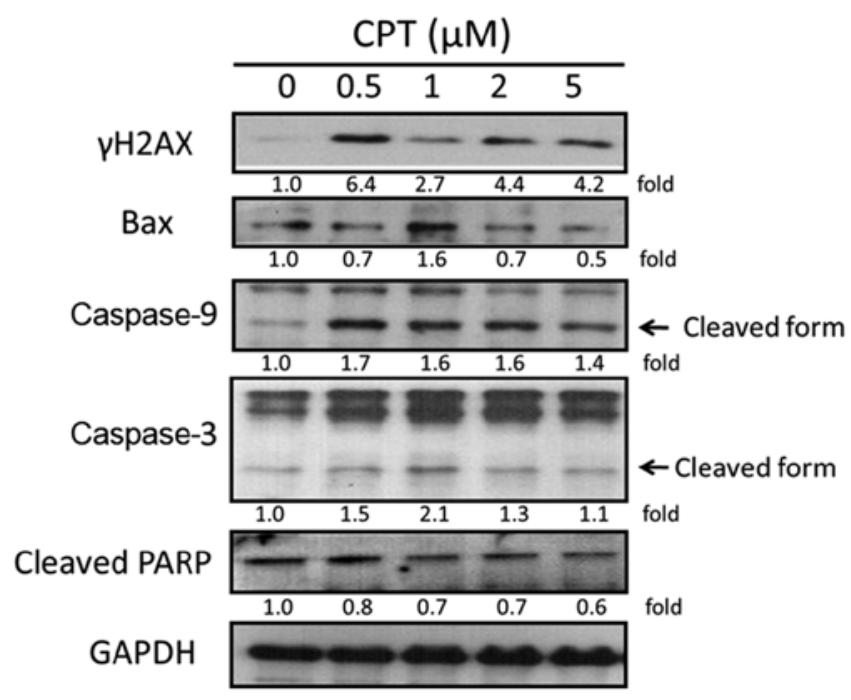

Figure 1. Effects of CPT on cell viability and apoptosis of NSCLC cells. (A) Viability of two non-small cell lung cancer cell lines, H1299 and H460, was determined by trypan blue exclusion assay. (B) Alterations in the expression levels of apoptosis-associated proteins and the DNA damage-sensor $\gamma \mathrm{H} 2 \mathrm{AX}$ in H1299 cells, as determined by western blotting. GAPDH was used as an internal control to ensure equal loading. Data are presented as the means \pm standard deviation of at least three independent experiments. a vs. a, $\mathrm{P}>0.05$; a vs. $\mathrm{b}, \mathrm{P}<0.05$; a vs. c, $\mathrm{P}<0.001$. $\gamma \mathrm{H} 2 \mathrm{AX}$, phosphorylated-H2A histone family, member $\mathrm{X}$ $\left(\mathrm{Ser}^{139}\right)$; Bax, B-cell lymphoma 2-associated X protein; CPT, camptothecin; PARP, poly (ADP-ribose) polymerase.

and cells were rinsed three times in $0.5 \%$ Triton-PBS and incubated for $1 \mathrm{~h}$ in the dark with a FITC-conjugated antimouse IgG secondary antibody (1:500, cat. no. GTX26816; Genetex, Inc.). Cells were then rinsed twice in $0.5 \%$ Triton-PBS and the cells were stained with $0.5 \mu \mathrm{g} / \mathrm{ml}$ DAPI (cat. no. 32670; Sigma-Aldrich; Merck KGaA) for $5 \mathrm{~min}$. Images were captured using a fluorescence microscope (TE2000-U; Nikon Corporation).

Fluorescence microscopy. The green fluorescent protein (GFP) fluorescence-tagged LC3 (LC3-GFP) construct was kindly provided by Dr Wei-Pang Huang (Department of Life Science, National Taiwan University, Taipei, Taiwan) (29). H1299 and H460 cells were seeded onto 6-well microplates and transfected with $1 \mu \mathrm{g}$ wild-type or mutant pEGFP-LC3 constructs using Lipofectamine ${ }^{\circledR}$ and PLUS ${ }^{\mathrm{TM}}$ reagent (Invitrogen; Thermo Fisher Scientific, Inc.), according to a previous study with minor modifications (29). A total of $48 \mathrm{~h}$ post-transfection, the medium was replaced with seletive medium containing $0.4 \mathrm{mg} / \mathrm{ml}$ (for $\mathrm{H} 460$ cells) and $0.8 \mathrm{mg} / \mathrm{ml}$ (for H1299 cells) Geneticin selective antibiotic (G418 Sulfate; cat. no 10131035; Gibco; Thermo Fisher Scientic, Inc.). Surviving colonies were picked 2 weeks later and amplified. Stable transfectants were examined for LC3-GFP expression and used in relevant experiments. Cells were seeded onto a cover glass slide chamber (Nunc ${ }^{\mathrm{TM}} \mathrm{Lab}^{-\mathrm{Tek}^{\mathrm{TM}}}$; Thermo Fisher Scientific, Inc.), and after the designated treatments, the cells were examined under a Nikon Eclipse TE2000U fluorescence microscope (Nikon Corporation). The GFP-LC3 puncta were quantified by counting the number of cells as described previously $(29,30)$. Briefly, the GFP-LC3 puncta in a single cell were manually counted under a fluorescence microscope. For each group, 50 cells were randomly selected to determine the average number of GFP-LC3 puncta/cells. The presented results were selected from experiments performed at least three times.

Statistical analysis. All experiments were performed at least in triplicate. Data were analyzed by multivariate analysis of variance. If a significant difference was found, a Holm-Sidak multiple comparison test was used to identify significant groups. Statistical analyses were conducted using SigmaPlot software version 12.0 (Systat Software, Inc., San Jose, CA, USA). $\mathrm{P}<0.05$ was considered to indicate a statistically significant difference.

\section{Results}

$I C_{50}$ values in NSCLC cell lines. The present study was conducted using two LCC cell lines, H1299 (p53-deleted, $p 53^{\text {null }}$ ) and $\mathrm{H} 460$ (wild-type p53-expressing, $p 53^{w t}$ ), since $\mathrm{CPT}$ is a recommended therapeutic treatment for advanced NSCLC (31). The $\mathrm{IC}_{50}$ values of CPT were initially determined in $\mathrm{H} 1299$ and $\mathrm{H} 460$ cells prior to examining the antitumor effects of CPT and the CPT-resistant effects of H1299 and $\mathrm{H} 460$ cells. The determined $\mathrm{IC}_{50}$ for CPT was $1 \mu \mathrm{M}$ in $\mathrm{H} 1299$ cells and $1 \mu \mathrm{M}$ in $\mathrm{H} 460$ cells (data not shown).

CPTfailed to induce a cytotoxic effect on drug-resistant H1299 and $H 460$ cell lines in a dose-responsive manner. Since CPT is able to inhibit tumor cell viability and metastasis of lung carcinoma cells (32) the present study aimed to determine its molecular/cellular mechanism. H1299 and H460 lung carcinoma cells were incubated for $24 \mathrm{~h}$ in the presence of various concentrations of CPT. As shown in Fig. 1A, the trypan blue assay demonstrated that CPT damaged cell viability of H1299 
A

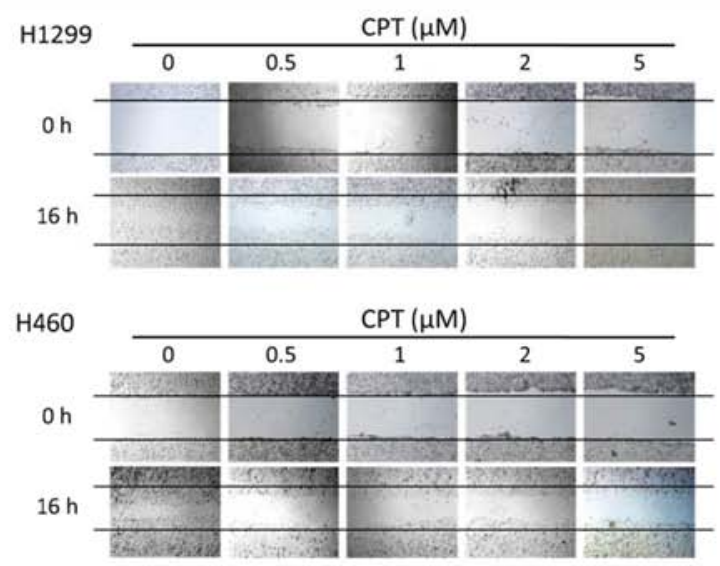

B

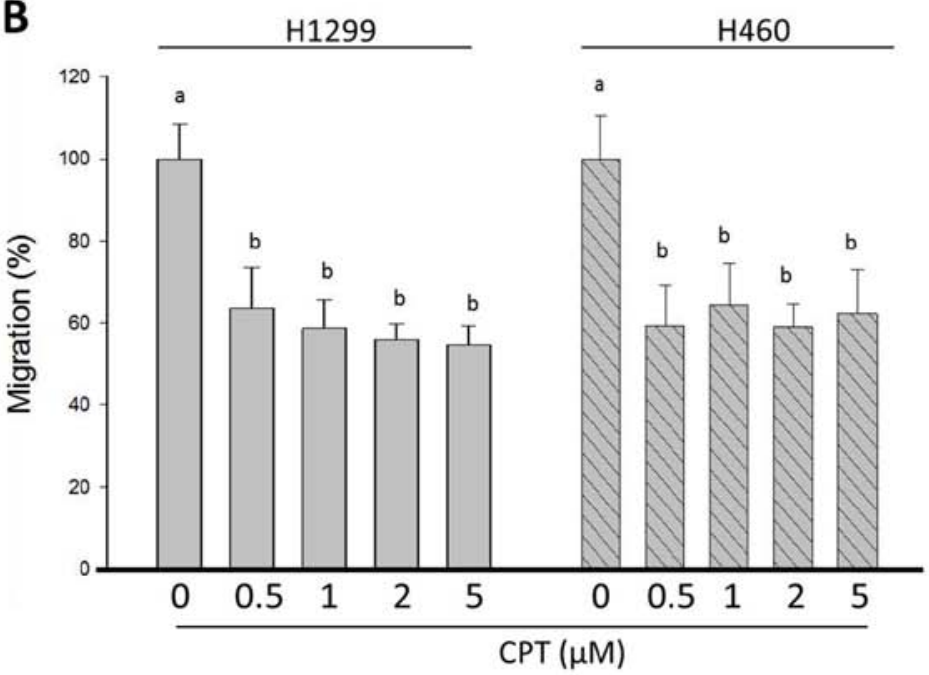

Figure 2. (A) Migration of H1299 and H460 cells following CPT treatment for $16 \mathrm{~h}$ was determined using a wound-healing assay. Magnification, x100. (B) Quantification of the wound-healing assay results. Data are presented as the means \pm standard deviation of at least three independent experiments. a vs. a, $\mathrm{P}>0.05$; a vs. b, $\mathrm{P}<0.05$. CPT, camptothecin.

and H460 cells. In H1299 cells, the percentage of viable cells decreased from $100 \pm 1.8 \%$ in the untreated group to $55.8 \pm 2.3$, $49.2 \pm 3.9,47.3 \pm 11.4$ and $39.2 \pm 4.6 \%$ in the presence of $0.5,1$, 2 and $5 \mu \mathrm{M}$ CPT, respectively. In $\mathrm{H} 460$ cells, the percentage of viable cells decreased from $100 \pm 0.0 \%$ in the untreated group to $47.4 \pm 4.9,44.46 \pm 4.5,47.07 \pm 3.3$ and $39.9 \pm 0.5 \%$ in the presence of $0.5,1,2$ and $5 \mu \mathrm{M}$ CPT, respectively; therefore, the susceptibility of the two lung carcinoma cells to CPT was considered similar.

Most types of cancer harbor significant patterns of relapse following treatment due to evolved resistance. It has been reported that cancer cells exist due to their resistance to cell death and the loss of their ability to undergo apoptosis-induced death, thus leading to uncontrolled proliferation (33). Evasion of apoptosis may contribute to tumor development and progression, and to treatment resistance, since the majority of anticancer therapies that are currently available, including CPT-based chemotherapy, primarily act by activating the apoptotic pathway in NSCLC (8). A better understanding of the pathway underlying tumor resistance to apoptotic cell death is required, in order to provide understanding of the molecular mechanisms underlying development of resistance to targeted therapy. Therefore, the present study detected apoptosis and DNA-damage-related protein expression in H1299 cells treated with various concentrations of CPT. The phosphorylation of $\mathrm{H} 2 \mathrm{AX}$ at $\mathrm{Ser}^{139}$, resulting in the formation of $\gamma \mathrm{H} 2 \mathrm{AX}$ puncta in the nuclei, is an early event in the cellular response to DNA damage. The expression levels of $\gamma \mathrm{H} 2 \mathrm{AX}$ were detected in order to evaluate DNA damage of H1299 cells. As shown in Fig. 1B, the results of western blotting indicated that, in the presence of $0.5 \mu \mathrm{M}$ CPT, the expression levels of the DNA damage biomarker $\gamma \mathrm{H} 2 \mathrm{AX}$ were increased, as were the expression levels of cleaved caspase-9 and caspase-3. Furthermore, $1 \mu \mathrm{M}$ CPT increased B-cell lymphoma 2 (Bcl-2)-associated X protein (Bax) and cleaved caspase-3 expression (Fig. 1B). These results indicated that low dosages of CPT induced apoptosis and DNA damage of H1299 cells; however, the protein expression levels of $\gamma \mathrm{H} 2 \mathrm{AX}$, Bax, cleaved caspase-9, cleaved caspase-3 and cleaved poly (ADP-ribose) polymerase (PARP) were not markedly increased by CPT in a dose-dependent manner. These observations suggested that H1299 NSCLC cells may eventually become resistant in response to higher concentrations of CPT. Therefore, $0.5 \mu \mathrm{M}$ CPT may be considered a reasonable dose due to its significant effect on cell viability; cells were treated with $0.5 \mu \mathrm{M}$ CPT in subsequent experiments.

The present study also determined the effects of various concentrations of CPT on the migration of H1299 and H460 cells using wound-healing assays. In the control group, the cells migrated into the wound area and the wound edges became indistinguishable; however, following the addition of CPT, cells exhibited slower wound healing (Fig. 2A). In response to various concentrations of CPT, H1299 cell migration was inhibited from $100.0 \pm 8.4 \%$ in the control group, to $63.5 \pm 9.9$, $58.7 \pm 6.8,55.85 \pm 4.0$ and $54.6 \pm 4.6 \%$ in response to $0,0.5,1$, 2 and $5 \mu \mathrm{M} \mathrm{CPT}$, respectively (Fig. 2B). The percentage of cell viability and wound healing was significantly decreased in $\mathrm{H} 1299$ cells in the presence of $0.5-5 \mu \mathrm{M}$ CPT compared with in the control group $(\mathrm{P}<0.05)$. However, there was no alteration in the percentage of cell viability and wound healing following CPT dosage accumulation, thus indicating that treatment did not affect growth and metastasis; in addition, the inhibitory effects of CPT on H1299 cells reached a plateau. Consistent with the results in H1299 cells, H460 cells were treated with the indicated concentrations of CPT for $24 \mathrm{~h}$, after which the migration rate of cells was significantly reduced compared with in the control group; however, no change in migration was detected as the CPT dosage accumulated (Fig. 2). These observations supported the finding that higher concentrations of CPT (1, 2 and $5 \mu \mathrm{M})$ exhibited no further inhibitory effect on cell viability and metastasis compared with the lower CPT concentration $(0.5 \mu \mathrm{M})$ on H1299 and H460 NSCLC cells.

A recent study suggested that when treated with chemotherapeutic agents, certain tumor cells fail to undergo 
A

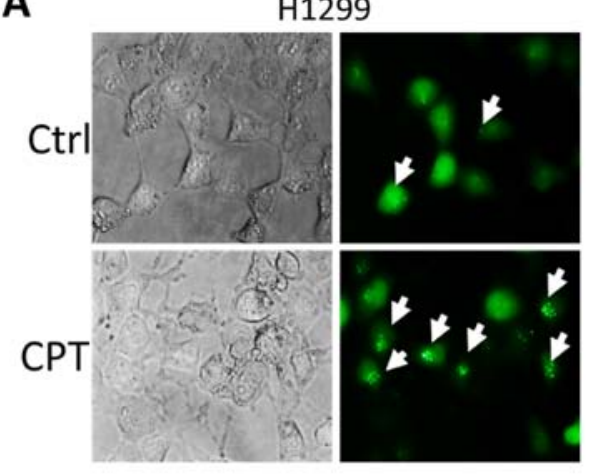

C

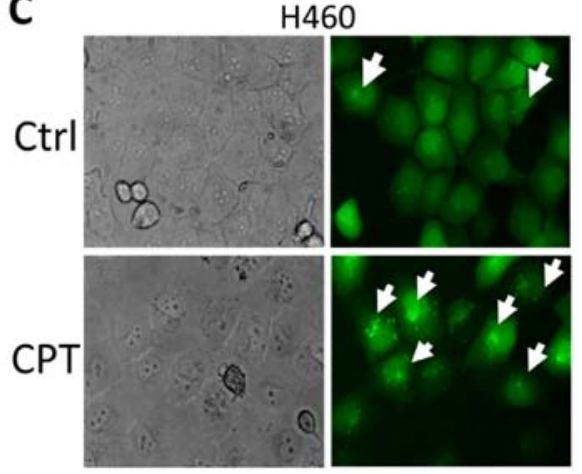

B

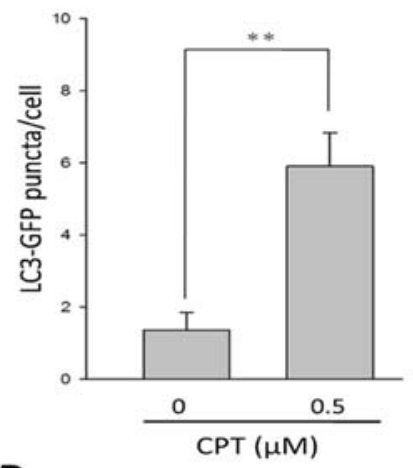

D

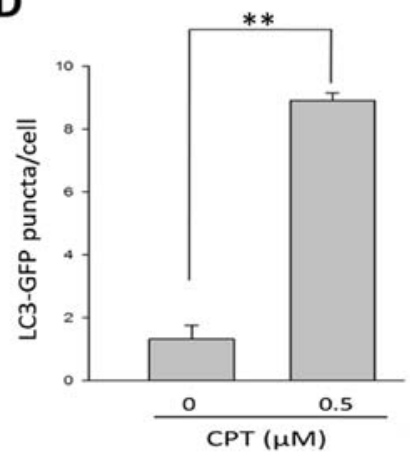

Figure 3. CPT treatment leads to accumulation of autophagic markers in two NSCLC cell lines. Increases in GFP-LC3 puncta were detected in (A and B) H1299 and (C and D) H460 cells cultured in the presence of $0.5 \mu \mathrm{M}$ CPT. (A and C) Magnification, x200. (B and D) GFP-LC3 puncta/cell was quantified following treatment of H1299 and H460 cells with CPT. Data are presented as the means \pm standard deviation. ${ }^{* *} \mathrm{P}<0.001 \mathrm{compared}$ with the Ctrl cells. CPT, camptothecin; Ctrl, control; GFP, green fluorescent protein; LC3, microtubule-associated proteins 1A/1B light chain 3.

apoptosis and instead undergo autophagy followed by delayed cell death (34). To determine whether autophagy is associated with the suppression of CPT-induced apoptotic cell death, the autophagic marker phosphatidylethanolamine-LC3 (LC3-II) was detected in $\mathrm{H} 1299$ cells in the presence of $0.5 \mu \mathrm{M}$ CPT. As

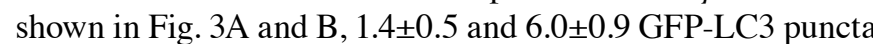
were detected in $\mathrm{H} 1299$ cells in the presence of 0 and $0.5 \mu \mathrm{M}$ CPT, respectively. These findings indicated that supplementation with $0.5 \mu \mathrm{M}$ CPT may lead to an enrichment of GPF-LC3 protein in $\mathrm{H} 1299$ cells $(\mathrm{P}<0.05)$, thus suggesting that $\mathrm{H} 1299$ cells respond to CPT by activating autophagy. Similar effects were detected on H460 NSCLC cells (Fig. 3C and D).

Since the present study demonstrated that CPT increased autophagy in H1299 cells, it was hypothesized that alterations in cell survival may be due to autophagy. The protein expression levels of mammalian target of rapamycin (mTOR), Atg3, LC3B, SQSTM/p62 and LAMP2, which are involved in the autophagic process, were also examined by western blot analysis (Fig. 4). The expression levels of Atg3 were slightly increased in response to $0.5,1$ and $2 \mu \mathrm{M} \mathrm{CPT}$, and appeared the same in the the control and $5 \mu \mathrm{M}$ CPT groups. Decreases in the expression levels of mTOR and p62 were detected in response to various CPT concentrations. LAMP2 was increased in response to 0.5 and $1 \mu \mathrm{M} \mathrm{CPT}$, and was only slightly decreased in response to $5 \mu \mathrm{M}$ CPT. Furthermore, the expression levels of the protein LC3B-I (an unprocessed form of LC3) and the cleaved protein LC3B-II (lipidated and autophagosome-associated form of LC3) were markedly increased in H1299 cells following CPT treatment at various concentrations compared with in the control group (Fig. 4).

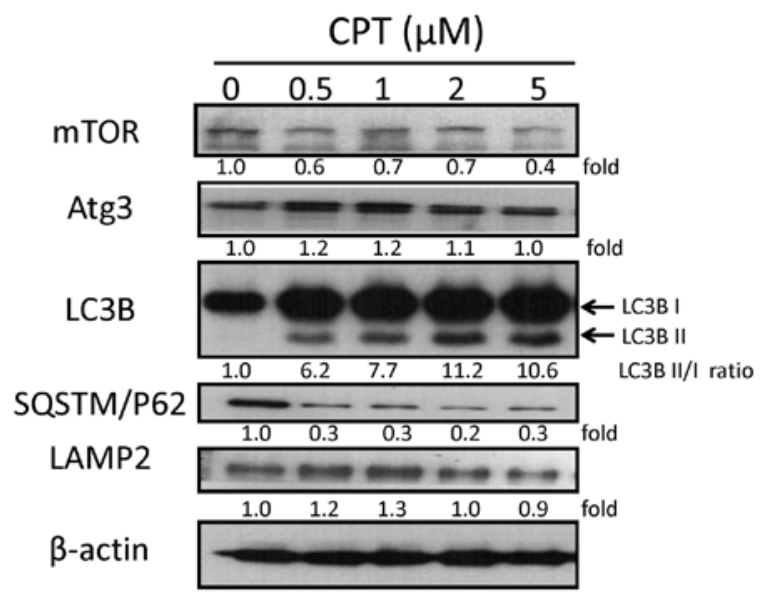

Figure 4. Expression of autophagic proteins in H1299 cells treated with various concentrations of CPT. Representative images of western blot analyses of mTOR, Atg3, LC3B, SQSTM/P62 and LAMP2 expression are presented. $\beta$-actin served as an internal control to ensure equal loading. Atg3, autophagy-related 3; CPT, camptothecin; LAMP2, lysosomal-associated membrane protein 2 ; LC3B, microtubule-associated proteins $1 \mathrm{~A} / 1 \mathrm{~B}$ light chain 3B; mTOR, mammalian target of rapamycin; SQSTM, sequestome-1.

These findings were consistent with detection of the increased formation of autophagosomes, and suggested that CPT may enhance autophagy in an H1299 NSCLC cell lines in a dosedependent manner.

3-MA blocks CPT-induced autophagy in H1299 lung cancer cells in a dose-dependent manner. To determine the role of 
A

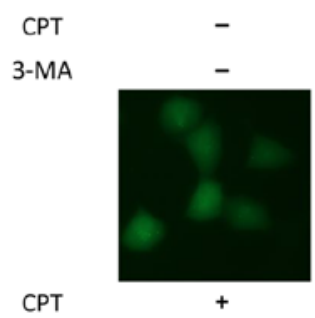

3-MA

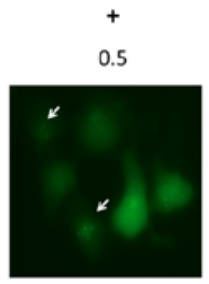

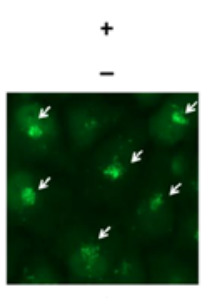

$+$

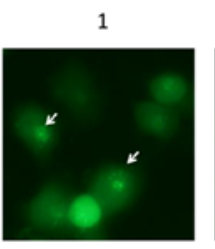

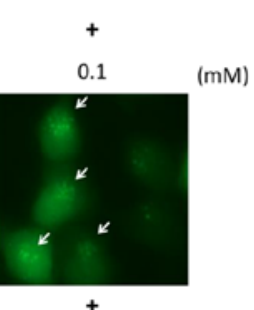

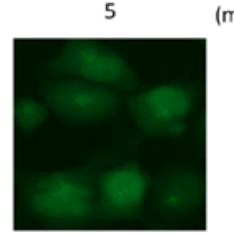

B

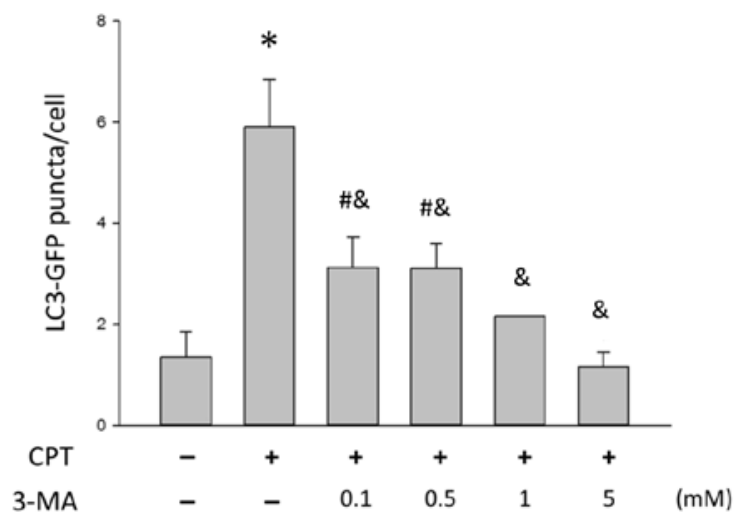

Figure 5. 3-MA treatment suppresses CPT-induced accumulation of autophagic markers in H1299 cells. (A) White arrows indicate GFP-LC3 puncta in H1299 cells following treatment with various concentrations of 3-MA, in the presence of $0.5 \mu \mathrm{M}$ CPT. Magnification, x200. (B) GFP-LC3 puncta/cell was observed under a microscope and counted. Data are presented as the means \pm standard deviation. ${ }^{*} \mathrm{P}<0.05$ vs. the control group; $\mathrm{P}<0.001$ vs. the control group; ${ }^{\&} \mathrm{P}<0.001$ vs. the CPT-treated group. 3-MA, 3-methyladenine; CPT, camptothecin; GFP, green fluorescent protein; LC3, microtubule-associated proteins 1A/1B light chain 3.

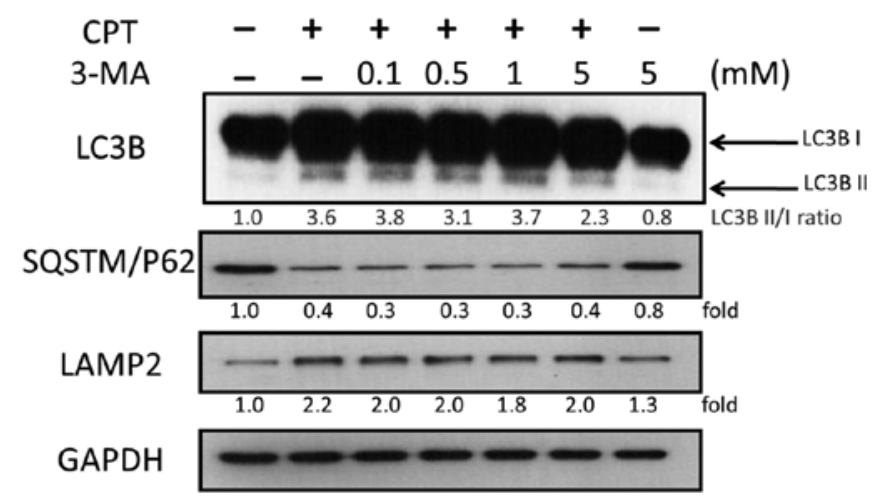

Figure 6. 3-MA treatment reduces CPT-induced autophagic protein expression in H1299 cells. The expression levels of autophagic proteins were detected in H1299 cells following treatment with the indicated concentrations of 3-MA in the presence of $0.5 \mu \mathrm{M}$ CPT. Representative images of western blot analyses of LC3B, SQSTM/P62 and LAMP2 expression are presented. GAPDH served as an internal control to ensure equal loading 3-MA, 3-methyladenine; CPT, camptothecin; LAMP2, lysosomal-associated membrane protein 2; LC3B, microtubule-associated proteins $1 \mathrm{~A} / 1 \mathrm{~B}$ light chain 3B; SQSTM, sequestome-1.

autophagy in CPT-treated NSCLC, the present study cotreated H1299 cells with various concentrations of the autophagy inhibitor 3-MA and $0.5 \mu \mathrm{M} \mathrm{CPT}$, in order to determine whether 3-MA blocked CPT-induced autophagy. As shown in Fig. 5, 3-MA had an effect on CPT-induced autophagy; treatment with CPT alone resulted in 5.91 \pm 0.9 GFP-LC3 puncta, whereas 3-MA induced a significant dose-dependent decrease in autophagy in $\mathrm{H} 1299$ cells $(\mathrm{P}<0.05)$. To further validate the inhibitory effects of 3-MA on CPT-induced autophagy, activation of $\mathrm{LC} 3 \mathrm{~B}$ and the expression of autophagic proteins were analyzed by western blotting. As shown in Fig. 6, 3-MA treatment reduced the accumulation of LC3B induced by $0.5 \mu \mathrm{M}$ CPT, but exhibited no marked effects on SQSTM/P62 and LAMP2 (Fig. 6). The ratio of LC3BII/I was decreased in a dose-dependent manner; the ratio of LC3BII/I was 3.8 and 2.3 in response to 0.1 and $5 \mathrm{mM} 3-\mathrm{MA}$, respectively. These findings indicated that 3-MA blocked CPT-induced autophagy in H1299 lung carcinoma cells.

3-MA enhances the anticancer effect of CPT via autophagy inhibition. As shown in Fig. 7A, the percentage of viable H1299 cells was $56.8 \pm 3.1,47.3 \pm 4.3$ and $22.3 \pm 5.3 \%$ following treatment with $0,0.5$ and $1 \mathrm{mM} 3-\mathrm{MA}$, in the presence of $0.5 \mu \mathrm{M}$ CPT, respectively, as opposed to $100.0 \pm 0.2 \%$ in the control group and $94.2 \pm 4.0 \%$ in the $1 \mathrm{mM} \mathrm{3-MA}$ group. Once CPT-induced autophagy was blocked, the cytotoxic effects of CPT were enhanced in H1299 cells. Furthermore, suppressing autophagy increased apoptosis, as determined using the Annexin V/PI staining assay. Following treatment with vehicle control, or $0,0.5,1$ and $5 \mathrm{mM} \mathrm{3-MA}$ in the presence of $0.5 \mu \mathrm{M}$ CPT for $24 \mathrm{~h}$, apoptosis was detected (Fig. 7B). In response to CPT, the percentage of apoptotic H1299 cells was $4.0 \pm 0.1 \%$; however, in response to CPT and 3-MA cotreatment, the percentage of apoptotic cells was $19.0 \pm 1.13,18.8 \pm 0.35$ and $15.4 \pm 0.35 \%$ following 3 -MA accumulation (Fig. 7B).

The present study indicated that there was a slight increase in apoptosis in the CPT group; however, in cells receiving CPT and 3-MA cotreatment apoptosis was significantly increased compared with in those receiving CPT only ( $\mathrm{P}<0.05$; Fig. 7B). These results suggested that, following cotreatment with 3-MA, CPT may efficiently induce apoptosis of CPT-resistant H1299 cells and CPT-induced autophagy may be suppressed. Since the major mechanism underlying CPT-induced cellular cytotoxicity and apoptosis is induction of DNA damage, the present study examined whether blocking autophagy affected the anti-lung cancer effects of CPT. As shown in Fig. 8, the expression levels of $\gamma \mathrm{H} 2 \mathrm{AX}$ were increased in response to CPT and 3-MA cotreatment compared with in cells treated with CPT or 3-MA alone. In addition, the expression levels of the apoptosis-associated protein caspase- 9 were detected by western blotting. The results indicated that activation of caspase-9 was enhanced in response to the suppression of CPT-induced autophagy by 3-MA. 
A

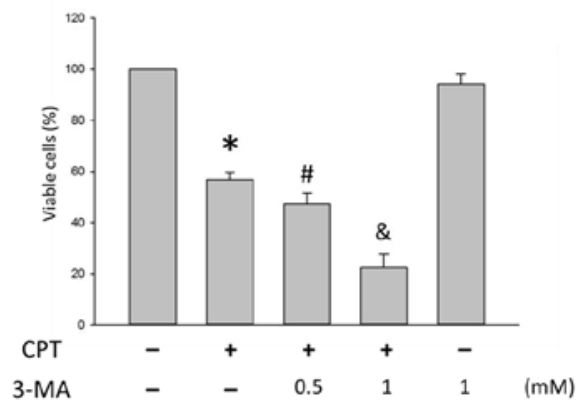

B

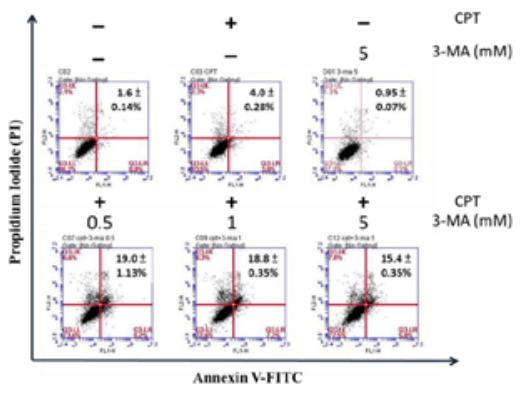

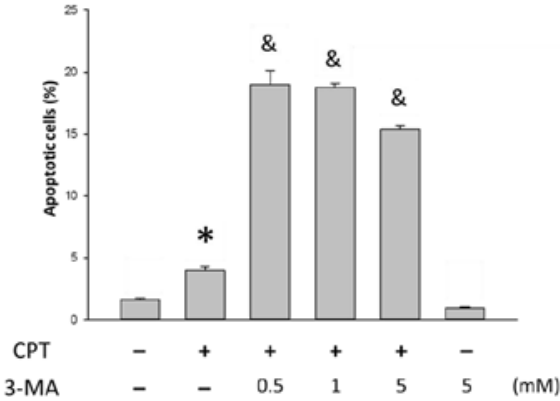

Figure 7. 3-MA enhances cytotoxicity and apoptosis in CPT-resistant H1299 cells. (A) H1299 cells were incubated in culture medium containing the indicated concentrations of 3-MA in the presence of $0.5 \mu \mathrm{M} \mathrm{CPT}$ for $24 \mathrm{~h}$. Subsequently, the cell viability was determined by trypan blue exclusion assay. (B) Apoptotic H1299 cells were stained with Annexin V-FITC and PI and were analyzed by flow cytometry (left panel). Apoptotic H1299 cells were quantified following exposure to various concentrations of 3-MA in the presence of $0.5 \mu \mathrm{M} \mathrm{CPT} \mathrm{(right} \mathrm{panel).} \mathrm{Data} \mathrm{are} \mathrm{presented} \mathrm{as} \mathrm{the} \mathrm{means} \pm$ standard deviation of at least three independent experiments. " $\mathrm{P}<0.001$ vs. the control group ; $\mathrm{P}<0.05$ vs. the CPT group; ${ }^{\circledR} \mathrm{P}<0.001$ vs. the CPT group. 3-MA, 3-methyladenine; $\mathrm{CPT}$, camptothecin; FITC, fluorescein isothiocyanate; PI, propidium iodide.

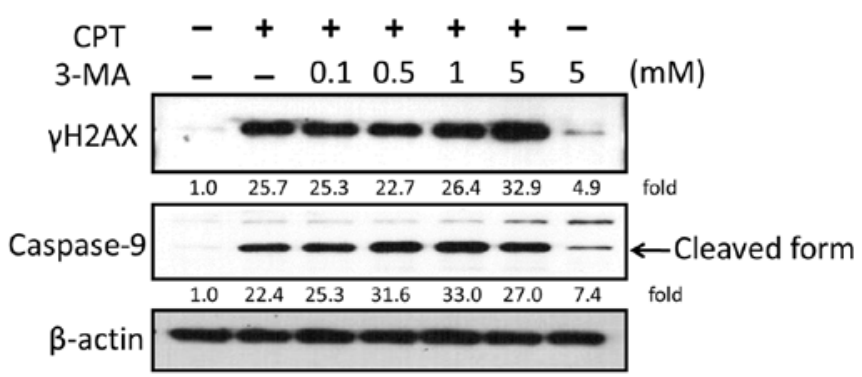

Figure 8. 3-MA treatment enhances the expression levels of apoptotic and DNA damage-associated proteins in CPT-resistant H1299 cells. The expression levels of apoptotic and DNA damage-associated proteins were detected in $\mathrm{H} 1299$ cells treated with various concentrations of 3-MA in the presence of $0.5 \mu \mathrm{M}$ CPT by western blotting. $\beta$-actin was used as an internal control to ensure equal loading. $\gamma \mathrm{H} 2 \mathrm{AX}$, phosphorylated-H2A histone family, member X $\left(\operatorname{Ser}^{139}\right)$; 3-MA, 3-methyladenine; CPT, camptothecin.

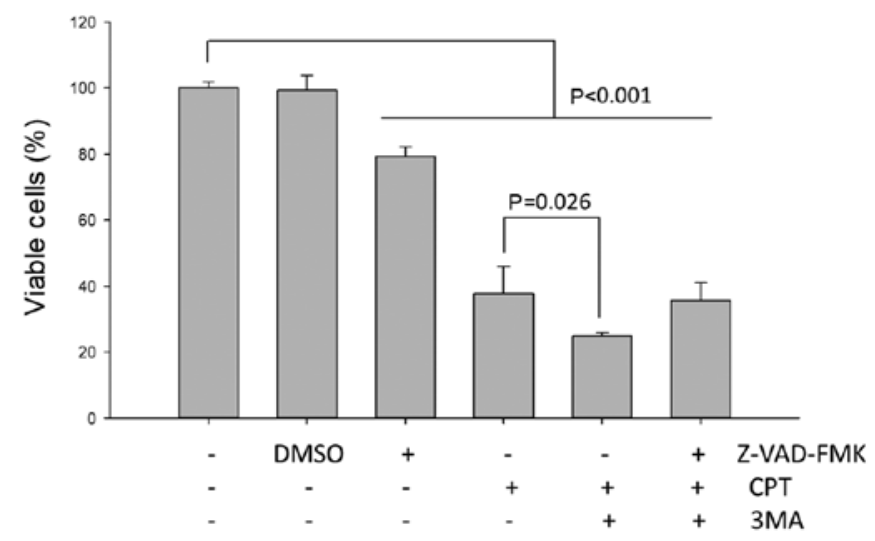

Figure 9. Effects of caspase inhibition on the viability of cells cotreated with CPT and 3-MA. NSCLC H1299 cells were pretreated with or without the pan-caspase inhibitor Z-VAD-FMK $(50 \mu \mathrm{M})$ for $2 \mathrm{~h}$, and were then treated with $0.5 \mu \mathrm{M}$ CPT and $0.5 \mathrm{mM} 3-\mathrm{MA}$ for $24 \mathrm{~h}$. Cell viability was determined using the trypan blue exclusion assay. DMSO was used as a vehicle control 3-MA, 3-methyladenine; CPT, camptothecin; DMSO, dimethyl sulfoxide.

Effects of a pan-caspase inhibitor. H1299 NSCLC cells were pretreated with or without the pan-caspase inhibitor Z-VAD-FMK for $2 \mathrm{~h}$ prior to treatment with CPT/3-MA for
24 h. Subsequently, cell viability was analyzed; the results indicated that pretreatment with the caspase inhibitor did not significantly affect the 3-MA-enhanced cytotoxic effects on CPT-treated H1299 cells (Fig. 9). These results indicated that 3-MA-enhanced cell death of NSCLC cell lines may not predominantly occur via a caspase-dependent pathway.

CPT-induced DNA damage is increased following autophagy blockade. To further demonstrate that the observed DNA-damaging effects were caused by blocking CPT-induced autophagy, $\gamma \mathrm{H} 2 \mathrm{AX}$ foci formation was analyzed in H1299 cells (Fig. 10A), and a $\gamma \mathrm{H} 2 \mathrm{AX} / \mathrm{PI}$ double staining assay was conducted in H1299 and H460 cells (Fig. 10B). $\gamma \mathrm{H} 2 \mathrm{AX}$ foci are generally regarded as markers of DNA double-strand breaks (35); therefore, increases in $\gamma \mathrm{H} 2 \mathrm{AX}$ foci indicate CPT-induced DNA damage in H1299. Notably, DNA damage was enhanced in H1299 and H460 cells in response to $\mathrm{CPT}$ and 3-MA cotreatment, and the effects of 3-MA on DNA damage were concentrationdependent.

\section{Discussion}

Drug resistance or chemoresistance is a phenomenon whereby cells undergo adaptive mutation under environmental stress (36). Chemoresistance disrupts anticancer drug actions and renders therapy ineffective. Chemoresistance is induced by numerous factors, including inhibition of drug absorption (37), epigenetic modifications (38), cell cycle alterations (39) and inhibition of apoptosis (40). Accordingly, one of the critical factors mediating chemoresistance is inhibition of cell apoptosis. To understand whether inhibition of apoptosis is attributed to a plateau of the cytotoxic effects of CPT, apoptotic factor expression was detected by western blot analysis. Notably, since low doses CPT increased caspase activation, decreases in the activation of caspase- 3 and caspase- 9 were detected in cells following treatment with high doses of CPT. In addition, other apoptotic factors, and the DNA damage marker $\gamma \mathrm{H} 2 \mathrm{AX}$, were also similarly reduced following treatment with increasing doses of CPT. These data indicated that when lung cancer H1299 cells were treated with a relatively 
A

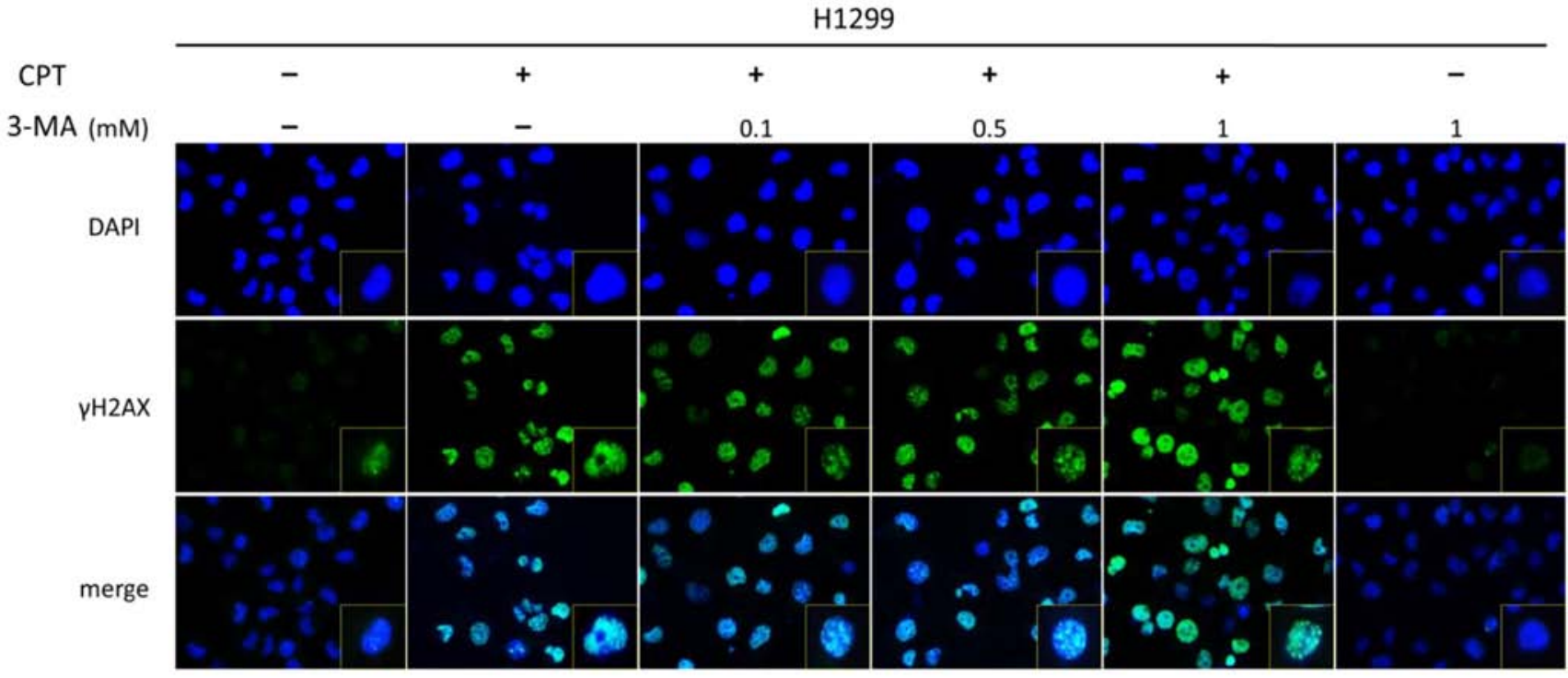

B
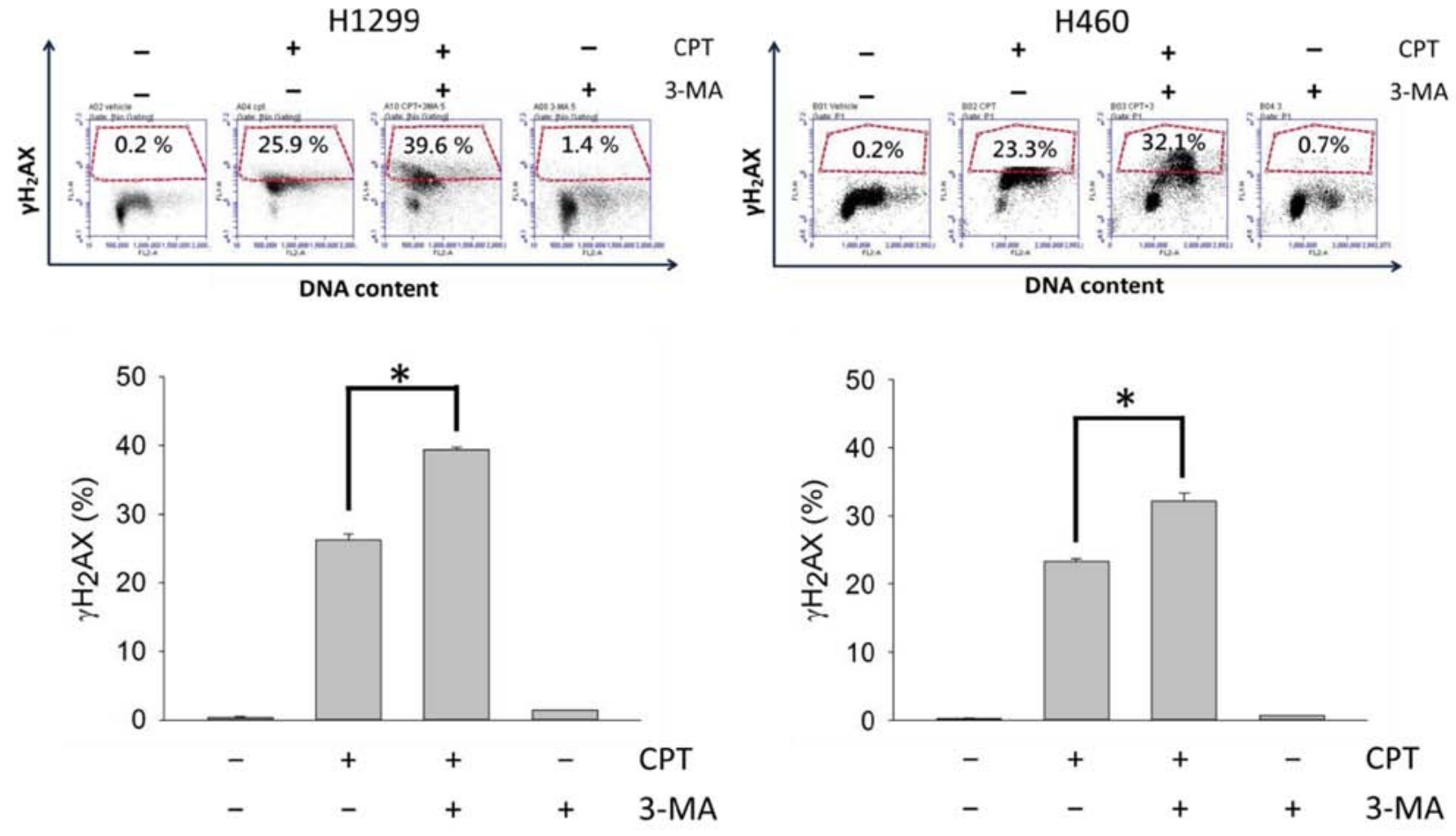

Figure 10. 3-MA treatment enhances $\gamma \mathrm{H} 2 \mathrm{AX}$ foci formation in CPT-resistant H1299 and H460 cells. (A) $\gamma \mathrm{H} 2 \mathrm{AX}$ foci (green fluorescence) formation was detected in H1299 cells following 24-h exposure to various concentrations of 3-MA in the presence of $0.5 \mu \mathrm{M}$ CPT. Nuclei were stained blue by DAPI. Magnification, x200. (B) Analysis of $\gamma \mathrm{H} 2 \mathrm{AX}$ intensity in $\mathrm{H} 1299$ (left panel) and $\mathrm{H} 460$ (right panel) cells stained with anti- $\gamma \mathrm{H} 2 \mathrm{AX}$-fluorescein isothiocyanate antibody and propidium iodide in the presence or absence of $5 \mu \mathrm{M} 3-\mathrm{MA}$ and $0.5 \mu \mathrm{M} \mathrm{CPT}$, as determined by flow cytometry. Percentage of $\gamma \mathrm{H} 2 \mathrm{AX}$-positive

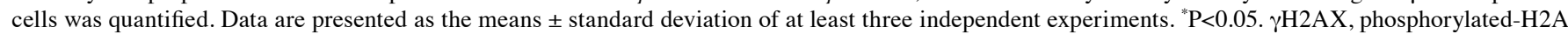
histone family, member X (Ser $\left.{ }^{139}\right)$; 3-MA, 3-methyladenine; CPT, camptothecin.

high concentration of CPT, the inhibition of apoptosis may enhance resistance of $\mathrm{H} 1299$ cells to antitumor CPT treatment. Despite the initial high responsiveness of cells to CPT and its derivatives (8-14), cancer cells often develop acquired resistance following treatment (41), which significantly limits the therapeutic efficacy of CPT. Methods for reversing CPT resistance are currently lacking; therefore, a better understanding of the mechanisms underlying such resistance is essential. A reduction in apoptotic cell death may be one of the factors that mediate chemoresistance, and the present study revealed that high concentrations of CPT may diminish apoptotic death and DNA damage in H1299 and H460 NSCLC cell lines.

In our previous studies, it was demonstrated that some chemosensitizers could reduce antagonism and sensitize cancer cells to CPT, thus enhancing CPT-induced anticancer effects under the $\mathrm{IC}_{50}$ concentration $(0.5 \mu \mathrm{M})(8,42)$. In the 


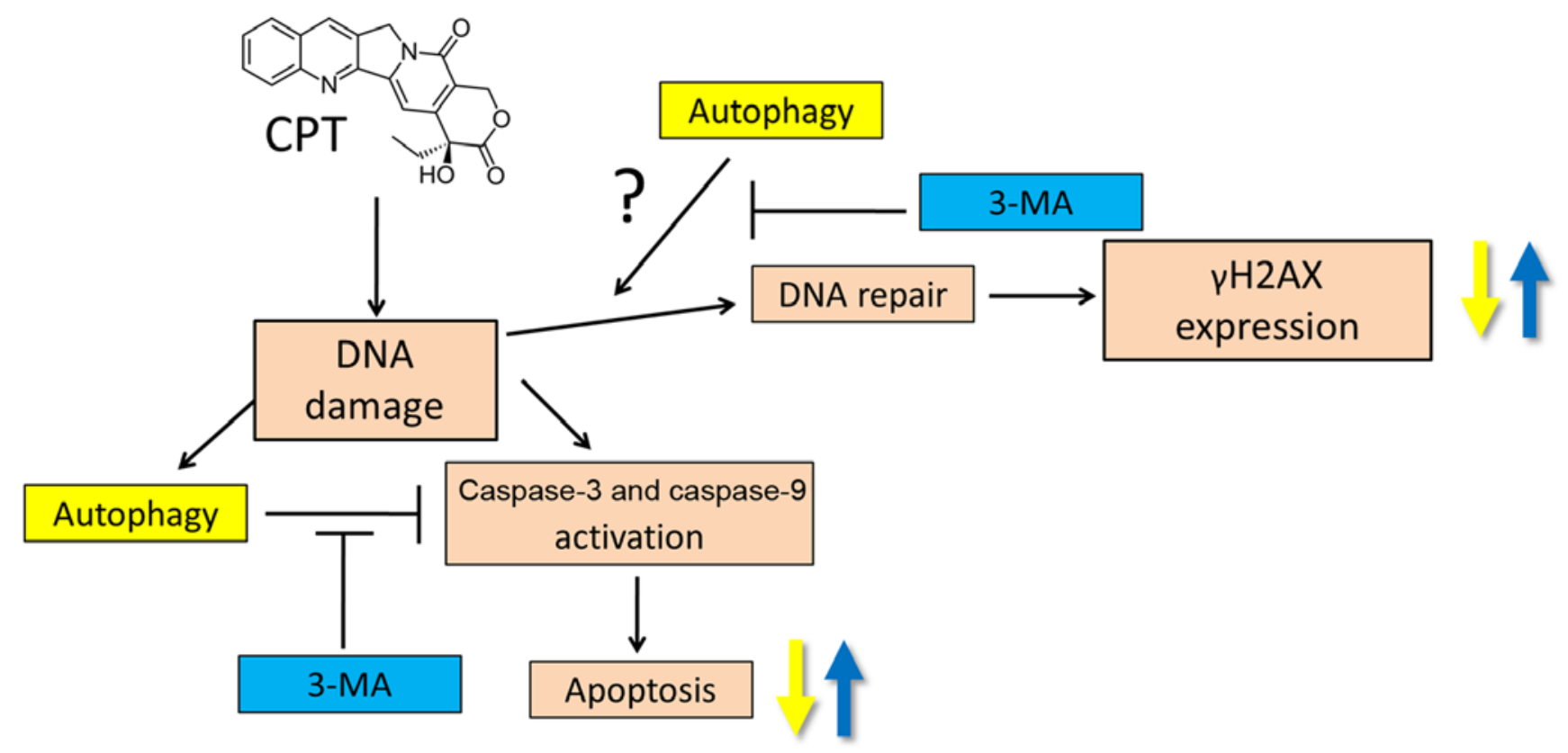

Figure 11. Proposed model of autophagy-mediated CPT resistance in NSCLC cells. H1299 NSCLC cells exhibit CPT resistance, in part, via CPT-induced autophagosome formation, which decreases cell cytotoxicity and apoptosis. CPT-induced autophagy may also attenuate DNA damage of lung cancer cells by decreasing $\gamma \mathrm{H} 2 \mathrm{AX}$ expression (yellow arrows). 3-MA suppressed autophagosome formation and enhanced the anticancer effects of CPT through increasing cell cytotoxicity and apoptosis (blue arrows). Elevated $\gamma \mathrm{H} 2 \mathrm{AX}$ foci also demonstrated that 3-MA-induced autophagy inhibition may participate in the anticancer activity of CPT via DNA damage, but not DNA repair. Accordingly, the present study may provide information regarding the association of autophagy with acquired CPT resistance in lung cancer cells, and the regulation of autophagy may be a promising strategy for treating lung cancer cells that constitutively exert activation of autophagy in response to CPT-based drugs, including irinotecan or topotecan. The question mark indicates further investigation is required. Solid lines represent theregulatory effects identified in the present study.

present study, there was no marked alteration in H1299 and $\mathrm{H} 460$ cell viability, wound closure, DNA damage and apoptotic cell death between 0.5 and $1 \mu \mathrm{M}$ CPT treatment. Conversely, CPT-induced formation of autophagosomes was increased and regulation of the expression of autophagy marker proteins was affected in H1299 and H460 lung carcinoma cells. As indicated by the reduction in apoptotic protein expression and the increase in autophagy at higher CPT concentrations, it was suggested that H1299 and H460 cells may eventually became less sensitive to higher concentrations of CPT. Since higher concentrations of CPT $\left(>\mathrm{IC}_{50}\right.$ : $1 \mu \mathrm{M})$ did not exhibit an increased anticancer effect, a lower dose of CPT $(0.5 \mu \mathrm{M})$ was considered a reasonable dosage for subsequent experiments.

Numerous studies have reported that autophagy induces chemoresistance against anticancer drugs by inhibiting apoptosis of cancer cells $(23,43)$. One suggested strategy to overcome acquired resistance to CPT and its derivatives is the inhibition of autophagosome formation $(44,45)$. A recent study demonstrated that defective autophagosome formation in $p 53^{\text {null }}$ colorectal cancer may enhance drug-induced apoptosis (46). In the present study, the antitumor effects of CPT were detected on both $\mathrm{H} 460 p 53^{w t}$ and $\mathrm{H} 1299 p 53^{\text {null }}$ lung cancer cell lines. A similar pattern was detected in $p 53^{\text {null }} \mathrm{H} 1299$ and $p 53^{w t} \mathrm{H} 460$ cells with regards to cell death, cell migration and autophagy in the presence of CPT; therefore, it may be suggested that CPT-mediated antitumor effects occur independently of p53 expression. On the basis of these results, further studies are required to verify the essential role of defective autophagosome formation in CPT-induced apoptosis in other NSCLC lines, such as $p 53^{w t} \mathrm{~A} 549$, and p53-mutated CL1-0 and CL1-5 lung adenocarcinoma cells.

To understand the role of autophagy in CPT-treated NSCLC cells, in the present study H1299 cells were cotreated with various concentrations of $3-\mathrm{MA}$ and $0.5 \mu \mathrm{M} \mathrm{CPT}$, and the effects of 3-MA on the suppression of CPT-induced autophagy were confirmed. 3-MA is an inhibitor of phosphatidylinositol 3-kinase (PI3K), which serves an essential role in controlling the activation of mTOR and the regulation of autophagy. The group of PI3K inhibitors includes 3-MA, wortmannin and LY294002. Among them, wortmannin is able to suppress autophagy regardless of nutrient status; however, 3-MA has been revealed to promote autophagy flux when used under nutrient-rich conditions for a prolonged period of time, whereas it is still capable of suppressing starvation-induced autophagy (47). Due to the dual roles of 3-MA in autophagy, it has been widely used as an autophagy inhibitor in various types of cancer therapy (48-50). The present study confirmed that 3-MA significantly inhibited cytoprotective autophagy in $\mathrm{H} 1299$ cells in a dose-dependent manner. The results of western blotting further revealed a marked decrease in LC3B expression in response to 3-MA, which may be associated with the reduction in autophagosome formation.

Since CPT-induced autophagy was suppressed by 3-MA, inhibition of H1299 cells was enhanced; in particular, apoptosis of H1299 cells was increased, as determined by trypan blue dye exclusion assay and Annexin V/PI staining. To further confirm that the observed apoptotic effects were produced by blocking CPT-induced autophagy, the expression levels of mitochondrial 
apoptotic proteins, including Bax, Bcl-2, caspase-3, caspase-9 and PARP, were detected via western blotting. The results demonstrated that activation of caspase- 9 was enhanced in response to inhibition of CPT-induced autophagy by 3-MA. However, there was no significant alteration in the expression levels of Bax, caspase- 3 and PARP in response to cotreatment with CPT and 3-MA (data not shown). Conversely, a marked decrease in the protein expression levels of Bcl-2 was detected following 3-MA dosage accumulation in the presence of $0.5 \mu \mathrm{M}$ CPT (data not shown). Therefore, the elevated Bax/Bcl-2 ratio indicated that 3-MA enhanced the susceptibility of H1299 cells to autophagy-inhibited apoptosis. These results suggested a significant improvement in CPT sensitivity following 3-MA cotreatment; this effect is most likely due to the suppression of autophagy and enhanced apoptosis of H1299 NSCLC cells.

Caspases are cysteine proteases that have critical roles in apoptosis $(51,52)$. The present study demonstrated that treatment with CPT and 3-MA activated caspase-9. However, pretreatment with a pan-caspase inhibitor did not significantly suppress CPT/3-MA-induced cell death, thus suggesting that CPT/3-MA-induced apoptosis was not associated with caspase-dependent pathways; this finding differs from previous reports. It has previously been reported that the apoptotic effects of CPT/3-MA are usually associated with the activation of caspase-3, caspase- 8 and caspase-9 in colon, liver (53) and lung cancer cells (54). The different pathways associated with CPT/3-MA-induced apoptosis may be due to various cell types, treatment duration and CPT/3-MA concentration.

Although it is widely believed that anticancer agents inhibit the viability of cancer cells through inducing apoptosis, accumulating evidence has revealed that other apoptosis-independent cell death modalities, such as autophagic cell death, may also contribute to cancer cell death, thus resulting in the inhibitory effects of anticancer drugs on cancer cells. For example, voacamine, which is a bisindolic alkaloid, induces apoptosis-independent autophagic cell death of the multidrugresistant human osteosarcoma cell line U-2 OS (55). Similarly, autosis, a newly identified non-apoptotic form of cell death, may contribute to cell death during autophagy (56). In the present study, 3-MA significantly enhanced CPT-induced cell death and increased its inhibitory effect on the viability of NSCLC cells; furthermore, apoptosis was markedly increased in CPT/3-MA-treated cells compared with in cells treated with CPT alone, thus confirming that 3-MA increased apoptosis of CPT-treated cells. Pretreatment with the pan-caspase inhibitor Z-VAD-FMK did not significantly affect the viability of NSCLC cells, thus suggesting that apoptosis may not be fully responsible for NSCLC cell death induced by CPT and 3-MA cotreatment. Additionally, non-apoptotic cell death, such as autosis or other forms of autophagic cell death, may contribute to the enhancing effects of 3-MA on CPT-induced proliferation inhibition and death of NSCLC cells.

Accumulating evidence has revealed that autophagy is capable of attenuating DNA damage by decreasing generation of ROS and modulating DNA repair activity $(57,58)$. Mitochondria, which are the major source of ROS, cause ROS production accompanied with DNA damage (59). Autophagy inhibits ROS production, in order to protect cells from DNA damage $(60,61)$; therefore, blocking autophagy may induce an excess generation of ROS, consequently leading to more severe DNA damage (62). When cells encounter DNA damage, they initiate DNA repair mechanisms to reduce it. Notably, autophagy is also involved in the process of DNA repair; autophagy induces the generation of ATP and recycles dNTP to improve DNA repair activity, whereas suppression of autophagy leads to decreased levels of checkpoint kinase 1 and a markedy diminished ability to repair DNA double-strand breaks (63).

According to previous results, the present study aimed to determine whether inhibiting autophagy affected the degree of DNA damage. Following inhibition of CPT-induced autophagy, the present study detected $\gamma \mathrm{H} 2 \mathrm{AX}$ through immunofluorescence and flow cytometry. The present study demonstrated that suppression of CPT-induced autophagy significantly increased $\gamma \mathrm{H} 2 \mathrm{AX}$ foci formation. These findings suggested that inhibition of autophagy increased DNA damage and $\gamma \mathrm{H} 2 \mathrm{AX}$ expression. In addition, DNA damage was only slightly increased in response to treatment with 3-MA alone. Therefore, it may be suggested that inhibition of autophagy by 3-MA promotes ROS generation leading to DNA damage; this may explain why $\gamma \mathrm{H} 2 \mathrm{AX}$ is upregulated in response to treatment with 3-MA alone.

In conclusion, the present study provided detailed insights into the CPT-resistant mechanisms of NSCLC cells. The results demonstrated that $\mathrm{CPT}$ failed to further induce cell cytotoxicity, metastasis-inhibiting effects, DNA damage and apoptotic death following dosage accumulation, and the inhibitory effects of CPT on H1299 and H460 cells reached an early plateau. Conversely, CPT increased the formation of autophagosomes in NSCLC H1299 cells in a dose-dependent manner, and the present study indicated that CPT-induced autophagy may serve a protective role in NSCLC with regards to DNA damage and apoptosis. Cotreatment with the autophagy inhibitor 3-MA blocked CPT-induced autophagy, and activated caspase-9 and $\gamma \mathrm{H} 2 \mathrm{AX}$, thereby enhancing induction of apoptosis and DNA damage in NSCLC cells. Taken together, 3-MA may serve as a promising clinical adjuvant to enhance CPT-based chemotherapies for the future treatment of lung cancer (Fig. 11).

\section{Acknowledgements}

The authors of the present study would like to thank the Center for Research Resources and Development at Kaohsiung Medical University (Kaohsiung, Taiwan) for support with instrumentation, including the confocal microscope and flow cytometer.

\section{Funding}

The present study was supported by grants from the Ministry of Science and Technology (MOST), Taiwan (grant nos. MOST105-2311-B-037-001, MOST106-2320-B-037-012, MOST107-2314-B-037-028-MY3 and 107-2320-B-037-023), the NSYSU-KMU Joint Research Project (grant nos. NS Y S UK M U 106 -P015, NSYSUKM U106-P019, NSYSUKMU107-P02 and NSYSUKMU107-P013), and the Aim for the Top Universities grants from Kaohsiung Medical University (grant nos. KMU-TP105A03 and KMU-M107002). 


\section{Availability of data and materials}

All data generated or analyzed during this study are included in this published article.

\section{Authors' contributions}

CCC initated the work. YHC, SHH and CCC designed experiments. $\mathrm{HWH}, \mathrm{KCH}$ and WL performed most of the assays. CYW, WPH, JYFC and BHC helped to acquire data and conduct statistical analysis. WPH helped conduct the transftection assay and analysed the autophagic puncta. YHC and CCC wrote the manuscript. All authors have read and approved the manuscript.

\section{Ethics approval and consent to participate}

Not applicable.

\section{Patient consent for publication}

Not applicable.

\section{Competing interests}

The authors declare that they have no competing interests.

\section{References}

1. Kayser G, Csanadi A, Kakanou S, Prasse A, Kassem A, Stickeler E, Passlick B and Zur Hausen A: Downregulation of MTSS1 expression is an independent prognosticator in squamous cell carcinoma of the lung. Br J Cancer 112: 866-873, 2015.

2. Chang A: Chemotherapy, chemoresistance and the changing treatment landscape for NSCLC. Lung Cancer 71: 3-10, 2011

3. Ling DJ, Chen ZS, Liao QD, Feng JX, Zhang XY and Yin TY: Differential effects of MTSS1 on invasion and proliferation in subtypes of non-small cell lung cancer cells. Exp Ther Med 12: 1225-1231, 2016.

4. McNeill PM, Wagman LD and Neifeld JP: Small bowel metastases from primary carcinoma of the lung. Cancer 59: 1486-1489, 1987.

5. Downey RJ, Asakura S, Deschamps C and Colby TV: Large cell carcinoma of the lung: Results of resection for a cure. J Thorac Cardiovasc Surg 117: 599-604, 1999.

6. Wall ME, Wani MC, Cook CE, Palmer KH, McPhail AT and Sim GA: Plant antitumor agents. 1. The isolation and structure of camptothecin, a novel alkaloidal leukemia and tumor inhibitor from Camptotheca acuminata. J Am Chem Soc 88: 3888-3890, 1966.

7. Wadkins RM, Bearss D, Manikumar G, Wani MC, Wall ME and Von Hoff DD: Topoisomerase I-DNA complex stability induced by camptothecins and its role in drug activity. Curr Med Chem Anticancer Agents 4: 327-334, 2004.

8. Chou HL, Fong Y, Wei CK, Tsai EM, Chen JY, Chang WT, Wu CY, Huang HW and Chiu CC: A quinone-containing compound enhances camptothecin-induced apoptosis of lung cancer through modulating endogenous ROS and ERK signaling. Arch Immunol Ther Exp (Warsz) 65: 241-252, 2017.

9. Kawakami T, Machida N, Yasui H, Kawahira M, Kawai S, Kito Y, Yoshida Y, Hamauchi S, Tsushima T, Todaka A, et al: Efficacy and safety of irinotecan monotherapy as third-line treatment for advanced gastric cancer. Cancer Chemother Pharmacol 78 : 809-814, 2016.

10. Kim M, Keam B, Kim TM, Kim HG, Kim JS, Lee SS, Shin SH, Kim MK, Park KU, Kim DW, et al: Phase II study of irinotecan and cisplatin combination chemotherapy in metastatic, unresectable esophageal cancer. Cancer Res Treat 49: 416-422, 2017.
11. Zhang B, Wang T, Yang S, Xiao Y, Song Y, Zhang N and Garg S: Development and evaluation of oxaliplatin and irinotecan co-loaded liposomes for enhanced colorectal cancer therapy. J Control Release 238: 10-21, 2016.

12. Keyvani-Ghamsari S, Rabbani-Chadegani A, Sargolzaei J and Shahhoseini M: Effect of irinotecan on HMGB1, MMP9 expression, cell cycle, and cell growth in breast cancer (MCF-7) cells. Tumour Biol 39: 1010428317698354, 2017.

13. Bruchim I, Ben-Harim Z, Piura E, Haran G and Fishman A: Analysis of two topotecan treatment schedules in patients with recurrent ovarian cancer. J Chemother 28: 129-134, 2016.

14. Kubo T, Fujiwara K, Hotta K, Okada T, Kuyama S, Harita S, Ninomiya T, Kamei H, Hosokawa S, Bessho A, et al: A phase II study of topotecan and cisplatin with sequential thoracic radiotherapy in elderly patients with small-cell lung cancer: Okayama Lung Cancer Study Group 0102. Cancer Chemother Pharmacol 78: 769-774, 2016.

15. Yang XQ, Li CY, Xu MF, Zhao $\mathrm{H}$ and Wang D: Comparison of first-line chemotherapy based on irinotecan or other drugs to treat non-small cell lung cancer in stage IIIB/IV: A systematic review and meta-analysis. BMC Cancer 15: 949, 2015.

16. Sugimoto $\mathrm{Y}$, Tsukahara S, Oh-hara T, Isoe T and Tsuruo T: Decreased expression of DNA topoisomerase I in camptothecinresistant tumor cell lines as determined by a monoclonal antibody. Cancer Res 50: 6925-6930, 1990.

17. Kawabata S, Oka M, Shiozawa K, Tsukamoto K, Nakatomi K, Soda H, Fukuda M, Ikegami Y, Sugahara K, Yamada Y, et al: Breast cancer resistance protein directly confers SN-38 resistance of lung cancer cells. Biochem Biophys Res Commun 280: 1216-1223, 2001.

18. Feeney GP, Errington RJ, Wiltshire M, Marquez N, Chappell SC and Smith PJ: Tracking the cell cycle origins for escape from topotecan action by breast cancer cells. Br J Cancer 88: 1310-1317, 2003.

19. Han JY, Lim HS, Yoo YK, Shin ES, Park YH, Lee SY, Lee JE, Lee DH, Kim HT and Lee JS: Associations of ABCB1, ABCC2, and ABCG2 polymorphisms with irinotecan-pharmacokinetics and clinical outcome in patients with advanced non-small cell lung cancer. Cancer 110: 138-147, 2007.

20. Czarny P, Pawlowska E, Bialkowska-Warzecha J, Kaarniranta K and Blasiak J: Autophagy in DNA damage response. Int J Mol Sci 16: 2641-2662, 2015.

21. Song $X$, Narzt MS, Nagelreiter IM, Hohensinner $P$, Terlecki-Zaniewicz L, Tschachler E, Grillari J and Gruber F: Autophagy deficient keratinocytes display increased DNA damage, senescence and aberrant lipid composition after oxidative stress in vitro and in vivo. Redox Biol 11: 219-230, 2017.

22. Maiuri MC, Zalckvar E, Kimchi A and Kroemer G: Self-eating and self-killing: Crosstalk between autophagy and apoptosis. Nat Rev Mol Cell Biol 8: 741-752, 2007.

23. Liang B, Liu X, Liu Y, Kong D, Liu X, Zhong R and Ma S: Inhibition of autophagy sensitizes MDR-phenotype ovarian cancer SK VCR cells to chemotherapy. Biomed Pharmacother 82: 98-105, 2016

24. Lu Y, Liu LL, Liu SS, Fang ZG, Zou Y, Deng XB, Long ZJ, Liu Q and Lin DJ: Celecoxib suppresses autophagy and enhances cytotoxicity of imatinib in imatinib-resistant chronic myeloid leukemia cells. J Transl Med 14: 270, 2016.

25. Vazquez-Martin A, Oliveras-Ferraros C and Menendez JA: Autophagy facilitates the development of breast cancer resistance to the anti-HER 2 monoclonal antibody trastuzumab. PLoS One 4: e6251, 2009

26. Chiu CC, Chou HL, Chen BH, Chang KF, Tseng CH, Fong Y, Fu TF, Chang HW, Wu CY, Tsai EM, et al: BPIQ, a novel synthetic quinoline derivative, inhibits growth and induces mitochondrial apoptosis of lung cancer cells in vitro and in zebrafish xenograft model. BMC Cancer 15: 962, 2015.

27. Chiu CC, Liu PL, Huang KJ, Wang HM, Chang KF, Chou CK, Chang FR, Chong IW, Fang K, Chen JS, et al: Goniothalamin inhibits growth of human lung cancer cells through DNA damage, apoptosis, and reduced migration ability. J Agric Food Chem 59: 4288-4293, 2011.

28. Tsai JR, Chong IW, Chen YH, Hwang JJ, Yin WH, Chen HL, Chou SH, Chiu CC and Liu PL: Magnolol induces apoptosis via caspase-independent pathways in non-small cell lung cancer cells. Arch Pharm Res 37: 548-557, 2014.

29. Tung YT, Hsu WM, Lee H, Huang WP and Liao YF: The evolutionarily conserved interaction between LC 3 and p62 selectively mediates autophagy-dependent degradation of mutant huntingtin. Cell Mol Neurobiol 30: 795-806, 2010. 
30. Ciechomska IA and Tolkovsky AM: Non-autophagic GFP-LC3 puncta induced by saponin and other detergents. Autophagy 3 : 586-590, 2007.

31. Saeki T, Mhashilkar A, Chada S, Branch C, Roth JA and Ramesh R: Tumor-suppressive effects by adenovirus-mediated mda-7 gene transfer in non-small cell lung cancer cell in vitro. Gene Ther 7: 2051-2057, 2000

32. Ramnath N, Yu J, Khushalani NI, Gottlieb RH, Schwarz JK, Iyer RV, Rustum YM and Creaven PJ: Scheduled administration of low dose irinotecan before gemcitabine in the second line therapy of non-small cell lung cancer: A phase II study. Anticancer Drugs 19: 749-752, 2008.

33. Holohan C, Van Schaeybroeck S, Longley DB and Johnston PG: Cancer drug resistance: An evolving paradigm. Nat Rev Cancer 13: 714-726, 2013

34. Fukuda T, Oda K, Wada-Hiraike O, Sone K, Inaba K, Ikeda Y, Makii C, Miyasaka A, Kashiyama T, Tanikawa M, et al: Autophagy inhibition augments resveratrol-induced apoptosis in Ishikawa endometrial cancer cells. Oncol Lett 12: 2560-2566, 2016.

35. Sánchez-Flores M, Pásaro E, Bonassi S, Laffon B and Valdiglesias V: $\gamma \mathrm{H} 2 \mathrm{AX}$ assay as DNA damage biomarker for human population studies: Defining experimental conditions. Toxicol Sci 144: 406-413, 2015.

36. Galhardo RS, Hastings PJ and Rosenberg SM: Mutation as a stress response and the regulation of evolvability. Crit Rev Biochem Mol Biol 42: 399-435, 2007.

37. Yamagata T, Kusuhara H, Morishita M, Takayama K, Benameur $\mathrm{H}$ and Sugiyama Y: Improvement of the oral drug absorption of topotecan through the inhibition of intestinal xenobiotic efflux transporter, breast cancer resistance protein, by excipients. Drug Metab Dispos 35: 1142-1148, 2007.

38. Furukawa Y and Kikuchi J: Epigenetic mechanisms of cell adhesion-mediated drug resistance in multiple myeloma. Int J Hematol 104: 281-292, 2016

39. Yan LH, Wang XT, Yang J, Lian C, Kong FB, Wei WY, Luo W, Xiao Q and Xie YB: Reversal of multidrug resistance in gastric cancer cells by CDX2 downregulation. World J Gastroenterol 19 : 4155-4165, 2013

40. Owen HC, Appiah S, Hasan N, Ghali L, Elayat G and Bell C: Phytochemical modulation of apoptosis and autophagy: Strategies to overcome chemoresistance in leukemic stem cells in the bone marrow microenvironment. Int Rev Neurobiol 135 : 249-278, 2017.

41. Beretta GL, Perego P and Zunino F: Mechanisms of cellular resistance to camptothecins. Curr Med Chem 13: 3291-3305, 2006.

42. Chou HL, Fong Y, Lin HH, Tsai EM, Chen JY, Chang WT, Wu CY, David Wang HM, Huang HW and Chiu CC: An acetamide derivative as a camptothecin sensitizer for human non-small-cell lung cancer cells through increased oxidative stress and JNK activation. Oxid Med Cell Longev 2016: 9128102 , 2016.

43. Wu HM, Shao LJ, Jiang ZF and Liu RY: Gemcitabine-induced autophagy protects human lung cancer cells from apoptotic death. Hai 194: 959-966, 2016.

44. Zhang JW, Zhang SS, Song JR, Sun K, Zong C, Zhao QD, Liu WT, Li R, Wu MC and Wei LX: Autophagy inhibition switches low-dose camptothecin-induced premature senescence to apoptosis in human colorectal cancer cells. Biochem Pharmacol 90: 265-275, 2014.

45. Li DD, Sun T, Wu XQ, Chen SP, Deng R, Jiang S, Feng GK, Pan JX, Zhang XS, Zeng YX, et al: The inhibition of autophagy sensitises colon cancer cells with wild-type p53 but not mutant p53 to topotecan treatment. PLoS One 7: e 45058, 2012.

46. Amin A, Bajbouj K, Koch A, Gandesiri M and Schneider-Stock R Defective autophagosome formation in p53-null colorectal cancer reinforces crocin-induced apoptosis. Int J Mol Sci 16: $1544-1561,2015$
47. Wu YT, Tan HL, Shui G, Bauvy C, Huang Q, Wenk MR, Ong CN, Codogno $P$ and Shen HM: Dual role of 3-methyladenine in modulation of autophagy via different temporal patterns of inhibition on class I and III phosphoinositide 3-kinase. J Biol Chem 285: 10850-10861, 2010.

48. Fiorini C, Menegazzi M, Padroni C, Dando I, Dalla Pozza E, Gregorelli A, Costanzo C, Palmieri M and Donadelli M: Autophagy induced by p53-reactivating molecules protects pancreatic cancer cells from apoptosis. Apoptosis 18: 337-346, 2013.

49. Sun Y, Liu Z, Zou X, Lan Y, Sun X, Wang X, Zhao S, Jiang C and Liu H: Mechanisms underlying 3-bromopyruvate-induced cell death in colon cancer. J Bioenerg Biomembr 47: 319-329, 2015.

50. Shin D, Kim EH, Lee J and Roh JL: RITA plus 3-MA overcomes chemoresistance of head and neck cancer cells via dual inhibition of autophagy and antioxidant systems. Redox Biol 13: 219-227, 2017.

51. Joseph B, Ekedahl J, Lewensohn R, Marchetti P, Formstecher P and Zhivotovsky B: Defective caspase-3 relocalization in non-small cell lung carcinoma. Oncogene 20: 2877-2888, 2001.

52. Zakeri Z and Lockshin RA: Cell death: History and future. Adv Exp Med Biol 615: 1-11, 2008.

53. Lin SY, Chang YT, Liu JD, Yu CH, Ho YS, Lee YH and Lee WS: Molecular mechanisms of apoptosis induced by magnolol in colon and liver cancer cells. Mol Carcinog 32: 73-83, 2001.

54. Seo JU, Kim MH, Kim HM and Jeong HJ: Anticancer potential of magnolol for lung cancer treatment. Arch Pharm Res 34: 625-633, 2011.

55. Meschini S, Condello M, Calcabrini A, Marra M, Formisano G, Lista P, De Milito A, Federici E and Arancia G: The plant alkaloid voacamine induces apoptosis-independent autophagic cell death on both sensitive and multidrug resistant human osteosarcoma cells. Autophagy 4: 1020-1033, 2008.

56. Liu Y and Levine B: Autosis and autophagic cell death: The dark side of autophagy. Cell Death Differ 22: 367-376, 2015.

57. Shao J, Yang X, Liu T, Zhang T, Xie QR and Xia W: Autophagy induction by SIRT6 is involved in oxidative stress-induced neuronal damage. Protein Cell 7: 281-290, 2016.

58. Lin W, Yuan N, Wang Z, Cao Y, Fang Y, Li X, Xu F, Song L, Wang J, Zhang H, et al: Autophagy confers DNA damage repair pathways to protect the hematopoietic system from nuclear radiation injury. Sci Rep 5: 12362, 2015.

59. Ray PD, Huang BW and Tsuji Y: Reactive oxygen species (ROS) homeostasis and redox regulation in cellular signaling. Cell Signal 24: 981-990, 2012

60. Rouschop KM, Ramaekers CH, Schaaf MB, Keulers TG, Savelkouls KG, Lambin P, Koritzinsky $M$ and Wouters BG: Autophagy is required during cycling hypoxia to lower production of reactive oxygen species. Radiother Oncol 92: 411-416, 2009.

61. Kaushik S and Cuervo AM: Autophagy as a cell-repair mechanism: Activation of chaperone-mediated autophagy during oxidative stress. Mol Aspects Med 27: 444-454, 2006.

62. Tokarz P, Piastowska-Ciesielska AW, Kaarniranta K and Blasiak J: All-trans retinoic acid modulates DNA damage response and the expression of the VEGF-A and MKI67 genes in ARPE-19 cells subjected to oxidative stress. Int J Mol Sci 17: 898, 2016

63. Liu EY, Xu N, O'Prey J, Lao LY, Joshi S, Long JS, O'Prey M, Croft DR, Beaumatin F, Baudot AD, et al: Loss of autophagy causes a synthetic lethal deficiency in DNA repair. Proc Natl Acad Sci USA 112: 773-778, 2015.

This work is licensed under a Creative Commons Attribution-NonCommercial-NoDerivatives 4.0 International (CC BY-NC-ND 4.0) License. 